\title{
Triângulo de fraudes de Cressey (1953) e teoria da agência: estudo aplicado a instituições bancárias brasileiras
}

\section{Cressey's fraud triangle (1953) and agency theory: study applied to brazilian banking institutions}

Triángulo del fraude de Cressey (1953) y teoría de la agencia: estudio aplicado a instituciones financieras de Brasil

\author{
Michele Rílany Rodrigues Machado \\ Doutora em Administração pela Universidade de Brasília \\ Professora Adjunta da Universidade Federal de Goiás \\ Endereço: Campus Samambaia - Prédio da FACE. Caixa Postal: 131 \\ CEP: 74.001-970 - Goiânia/GO - Brasil \\ E-mail: michelerilany@gmail.com \\ Telefone: (62) 3521-1390

\section{Ivan Ricardo Gartner} \\ Pós-Doutor em Administração (FEA-USP) e Pesquisa Operacional (FernUni Hagen) \\ Doutor em Engenharia de Produção pela Universidade Federal de Santa Catarina \\ Professor Titular da Universidade de Brasília - UNB \\ Endereço: Campus Darcy Ribeiro, FACE, s. B1-47/7, Asa Norte \\ CEP: 70.910-900 - Brasília/DF - Brasil \\ E-mail: irgartner@hotmail.com \\ Telefone: (61) 3107-0812
}

Artigo recebido em 09/05/2016. Revisado por pares em 29/08/2016. Reformulado em 30/03/2017. Recomendado para publicação em 26/05/2017 por Carlos Eduardo Facin Lavarda (Editor-Chefe). Publicado em 31/08/2017. 


\section{Resumo}

Esta pesquisa examinou se o triângulo de fraude de Cressey (1953) e a teoria de agência, em conjunto, possibilitam investigar a ocorrência de fraudes corporativas em instituições bancárias brasileiras. Foram formuladas seis hipóteses de pesquisas, segregadas nas dimensões do triângulo de fraude - pressão, oportunidade e racionalização - e mensuradas a partir de variáveis extraídas da teoria da agência, criminologia e estudos empíricos sobre fraudes. A identificação da probabilidade de ocorrência de fraudes foi operacionalizada a partir de regressões logísticas multinomiais, aplicadas a dados de 44 bancos, no período de janeiro/2001 a dezembro/2012. Para a dimensão de pressão, confirmou-se a hipótese $\mathrm{n}^{\mathrm{o}} 01$, ao indicar que quanto menor o desempenho anterior da instituição, maior a probabilidade de ocorrência de fraudes. Na dimensão de oportunidade, a hipótese $\mathrm{n}^{\circ} 03$ foi confirmada, ao colocar em evidência que baixos indicadores de governança corporativa aumentam a probabilidade de ocorrência de fraudes. Na dimensão de racionalização, confirmou-se a hipótese $\mathrm{n}^{0} 06$, portanto, a predominância do gênero feminino na gestão restringe a probabilidade de fraudes. Conclui-se, que o triângulo de Cressey, aliado à teoria da agência, constitui-se numa ferramenta apropriada para dirigir a investigação de ocorrência de fraudes corporativas em instituições bancárias.

Palavras-Chave: Instituições Bancárias; Fraudes Corporativas; Teoria da Agência; Economia do Crime; Triângulo de Fraude

\section{Abstract}

This research examined if Cressey's (1953) fraud triangle and the agency theory, jointly, enables investigate corporate fraud occurrence in Brazilian banking institutions. It was formulated six research hypotheses were segregated in fraud triangle-pressure, opportunity and rationalization - and measured by variables taken from the agency theory, criminology and empirical papers on corporate fraud. The identification of probability of fraud occurrence was operationalized from multinomial logistic model, applied to data of 44 banking, for the period between January 2001 and December 2012. For element pressure, hypotheses No. 01 was confirmed, since this showed that the lower an institution's previous performance, the greater probability there is of fraudulent events occurring in the future. In the element of opportunity, the hypothesis No. 03 was confirmed, which showed that low corporate governance indicators increased the possibility of fraud occurrences. In rationalization element, the hypothesis No. 08 was confirmed, therefore, the predominance of women in management reduces the probability of fraud. We thereby conclude that Cressey's Triangle, when combined with the theory of agency is an appropriate research instrument to use when carrying out an investigation into corporate fraud occurrence in banking institutions.

Keywords: Banking Institutions; Corporate Fraud; Theory of Agency; Economic Crime; Fraud Triangle

\section{Resumen}

El presente trabajo analiza si es posible investigar la comisión de fraudes corporativos en instituciones financieras de Brasil mediante el triángulo del fraude de Cressey (1953) y la teoría de la agencia. A partir de los tres vértices del triángulo, -presión, oportunidad y justificación- se presentan seis hipótesis, cuantificadas mediante variables extraídas de la teoría de la agencia, la criminología y otros estudios empíricos sobre este tema. Para identificar la probabilidad de que ocurra un fraude se recurrió al uso de regresiones logísticas de tipo multinomial en datos procedentes de 44 agencias bancarias desde enero de 2001 hasta diciembre de 2012. El vértice referido a la presión confirma la hipótesis $n^{o} 1$ al señalar que cuanto menor sea el rendimiento anterior de una institución, mayor es la probabilidad de cometer fraude. La hipótesis $n^{\circ} 3$, ubicada en el vértice de la oportunidad, evidencia que cuanto 
menos nivel tengan los directivos de una corporación mayor probabilidad existe de delinquir. En el último vértice referido a la justificación, la hipótesis $n^{\circ} 8$ apunta a que la presencia predominante de mujeres en puestos de gestión disminuye la probabilidad de fraude. Se confirma que el modelo triangular diseñado por Cressey junto a la teoría de la agencia constituye una apropiada herramienta de detección de posibles fraudes corporativos en bancos.

Palabras clave: Instituciones Bancarias; Fraudes Corporativos; Teoría de la Agencia; Economía del Crimen; Triángulo de Fraude

\section{Introdução}

Como Posner (2007) mencionou, a tarefa da Economia é explorar as implicações de supor que o homem é um maximizador racional de seus objetivos, de suas satisfações, e, portanto, do seu próprio interesse. Dada a constatação de Posner (2007), decorrente da análise da lei na perspectiva econômica, questiona-se até que ponto o indivíduo buscará o aumento de sua satisfação, quando imbuído de poder para tomar decisões em uma corporação.

Esse questionamento é amplamente discutido pela teoria da agência. Para esta teoria, uma relação de agência surge entre duas (ou mais) partes quando um, o agente, atua para ou em nome do principal, em um determinado domínio de problemas de decisão (ROSS, 1973). Logo, os agentes receberão poder para tomar decisões em nome dos proprietários. Os proprietários, ao delegarem poder, terão a expectativa de que seus objetivos e interesses sejam atendidos.

Jensen e Meckling (1976), ao seguir o pensamento de Alchian e Demsetz (1972) e Goldberg (1976), asseveram que a relação de agência é regida por termos contratuais. Os autores, no entanto, afirmam que as duas partes, principal e agente, são maximizadoras de utilidade e possuem diferentes objetivos e interesses, como, também, preferências distintas em relação ao risco de investimento.

Desse modo, conforme afirmam Jensen e Meckling (1976), existe uma boa razão para acreditar que o agente não agirá sempre no melhor interesse do principal, o que ocasionará custos com problemas de agência. Esses custos estão relacionados ao monitoramento das ações dos agentes pela adoção de sistemas de incentivo e remuneração, e de mecanismos de governança corporativa, despesas de concessão de garantias contratuais por parte do agente e do custo residual.

Além dos custos de agência, citados por Jensen e Meckling (1976), pode-se afirmar que entre principal e agente existe uma relação de confiança, em que o principal acredita que o agente trabalhará com a finalidade de atender aos objetivos do principal. Todavia, essa confiança poderá ser quebrada pelo agente quando este, de modo ilícito, buscar a maximização do seu próprio interesse.

O estudo da quebra de confiança foi marcado pelo trabalho de Cressey (1953), o qual, por intermédio de entrevistas com fraudadores, elaborou sua hipótese conhecida como triângulo de fraude. Cressey (1953) abandonou o conceito de embezzlement, termo usado pela literatura, substituindo-o por violação criminal da confiança financeira. Ao ampliar a visão da fraude, o autor enquadrou nesse novo conceito todo indivíduo que assumiu uma posição de confiança de boa fé, mas a violou ao cometer um crime.

A hipótese formulada por Cressey (1953) baseia-se na proposição de que pessoas que ocupam cargos de confiança tornam-se violadores, quando se veem com um problema financeiro não compartilhado, e estão cientes de que podem resolvê-lo secretamente pela violação do cargo de confiança. Para tal, os violadores são capazes de aplicar a sua própria conduta em situações que os capacitam a ajustar suas concepções de si mesmos como usuários 
ou proprietários dos fundos confiados.

Essa hipótese é apresentada na literatura da área de gestão em três dimensões: pressão, oportunidade e racionalização e, em razão desse fato, foi reconhecida como triângulo de fraude. A pressão, também denominada como motivação, é decorrente dos problemas financeiros não compartilhados. A oportunidade pressupõe que os fraudadores têm o conhecimento e a oportunidade para cometer fraude. Enquanto a racionalização é o processo no qual um fraudador classifica o ato de perpetrar uma fraude como aceitável e justificável, tendo em vista a solução de seu problema não compartilhado.

Percebe-se que o triângulo de fraude elaborado por Cressey (1953) está relacionado com a teoria da agência, dado que uma das premissas desse triângulo é que o fraudador assumiu uma posição de confiança. Portanto, o fraudador é um agente do principal que violou a sua posição de confiança financeira ao fazer uso das oportunidades identificadas para a realização de uma fraude. Essas oportunidades geralmente estão interligadas à existência de pontos fracos na governança corporativa da organização. Pontos de fragilidade representam um monitoramento imperfeito por parte da corporação nas atividades dos gestores.

Assim, a teoria da agência e o triângulo de fraude parecem contribuir para a identificação de variáveis que possibilitem a mensuração da probabilidade de ocorrência de fraudes nas corporações.

Dessa forma, essa pesquisa objetiva examinar se o triângulo de fraude de Cressey (1953) e a teoria de agência, em conjunto, possibilitam investigar a ocorrência de fraudes corporativas em instituições bancárias brasileiras. Para isso, foram formuladas hipóteses de pesquisas segregadas nas dimensões do triângulo de fraudes e mensuradas a partir de variáveis extraídas da teoria da agência, criminologia e estudos empíricos sobre fraudes corporativas. Destaca-se que foram extraídas variáveis da área de criminologia em função do estudo realizado por Cressey (1953) ser realizado nesta área.

Ressalta-se que as instituições bancárias foram escolhidas em função de sua importância para o contexto econômico, como intermediadores financeiros e fornecedores de capital externo às demais atividades do mercado. Assim, prejuízos de uma fraude em um grande banco podem ser sentidos pelo restante da economia brasileira.

Esta pesquisa está estruturada em cinco seções. A primeira, destinada a apresentar a problemática da pesquisa. A segunda seção evidencia as hipóteses de pesquisa e suas fundamentações teóricas. A terceira demonstra a metodologia aplicada. A quarta evidencia os resultados da pesquisa e a quinta contempla as principais conclusões obtidas.

\section{Fundamentação Teórica}

O triângulo de fraudes, é resultado do estudo de Cressey (1953). Este estudo, por intermédio de entrevistas, postulou a seguinte hipótese final:

Pessoas confiáveis se tornam violadores da confiança quando elas se consideram como tendo um problema financeiro que não pode ser compartilhado, e estão cientes de que este problema pode ser resolvido secretamente pela violação de confiabilidade financeira e conseguem aplicar, à sua própria conduta, verbalizações que lhes possibilitem ajustar seus conceitos de si mesmas como pessoas confiáveis como usuários de fundos e propriedades que lhes foram confiados (CRESSEY, 1953, p.30).

De acordo com Cressey (1953), a ocorrência de fraudes é condicionada pela existência conjunta das três dimensões: pressão, oportunidade e racionalização. A pressão corresponde a problemas financeiros não compartilhados pelo indivíduo, como: medo de perder a ocupação atual, o alcance ou manutenção de um dado padrão de vida e problemas pessoais. A oportunidade à existência de conhecimento necessário e a posse de informações sobre os pontos 
falhos de governança corporativa e a oportunidade de resolver o problema não compartilhado. E a racionalização é o processo de racionalizar o ato como justificável e/ou aceitável e "correto".

Os próximos subitens relacionam as hipóteses elaboradas para cada dimensão do triângulo de fraude de Cressey (1953), pressão, oportunidade e racionalização, bem como sua fundamentação teórica.

\subsection{Hipóteses da Dimensão de Pressão do Triângulo de Fraude}

Cressey (1953) observou que em todos os casos de violação da confiança analisados, o violador considerou que um problema financeiro enfrentado por ele, não poderia ser compartilhado com outras pessoas que, de um ponto de vista mais objetivo, provavelmente poderiam ter contribuído para a solução do problema.

Conforme afirma Cressey (1953), muitas situações diferentes são consideradas por um indivíduo na produção de problemas financeiros não compartilhados. As pressões, derivadas desses problemas, criam na pessoa de confiança o desejo por um resultado específico para solucionar o problema, que pode ser por intermédio da violação criminal da confiança financeira (CRESSEY, 1953).(???)

Ainda segundo Cressey (1953), todos os problemas financeiros não compartilhados estão relacionados à manutenção ou à procura de um status de comportamento dos violadores. Esse status poderá ser de ordem pessoal ou profissional como problemas resultantes de fracassos pessoais, alto nível de padrão de vida, este incompatível com a remuneração recebida, a relação entre empregado e empregador, pressões sobre o desempenho da empresa.

Ao seguir o triângulo de fraudes, as normas de auditoria, Resolução CFC n ${ }^{\circ} 1.207$ de 2009 e SAS n ${ }^{\circ} 99$, esclarecem que pode existir um incentivo ou pressão para produzir uma informação financeira fraudulenta quando a administração sofre pressão, de fontes externas ou internas, para alcançar metas de ganhos ou resultados financeiros previstos. Da mesma forma, também, podem existir incentivos para se apropriarem de ativos porque, por exemplo, esses indivíduos estão vivendo além de suas possibilidades.

Como fontes internas e externas de pressão, destacam-se dois itens que podem servir como indicadores da dimensão de pressão: o desempenho a ser alcançado pelos agentes e a remuneração percebida, que influenciará no padrão de vida desses agentes.

\subsubsection{Hipótese $N^{o}$ 01: Desempenho da Entidade}

Macey (1991) argumenta que gestores com autointeresse se envolverão em condutas criminosas, em nome de suas organizações, não para beneficiar os acionistas, mas para manter suas ocupações. Ainda segundo o autor, a ameaça de um desempenho abaixo do ideal poderá levar os gerentes a preferirem um maior nível de risco para elevarem o desempenho da empresa. Tal fato pode levar o gestor a manipular os demonstrativos financeiros com o objetivo de aumentar o desempenho da instituição, alcançando, dessa forma, as metas de desempenho fixados pelos proprietários e propiciando a manutenção de sua ocupação atual.

A argumentação de Macey (1991) corrobora os achados de Alexander e Cohen (1996), os quais encontraram evidências de que os desempenhos anteriores das empresas afetam a ocorrência de crimes corporativos. Assim, os gestores podem reconhecer que eles serão destituídos de sua ocupação, a menos que mantenham o desempenho de suas empresas acima do esperado (MACEY, 1991). Portanto, pode-se inferir que o desempenho abaixo do ideal será um fator de pressão para os gestores das organizações.

$\mathrm{Na}$ mesma linha de raciocínio, os gestores podem se sentir pressionados a aumentar a 
participação da empresa no mercado, ao se implicar em decisões de alto risco para garantir a competitividade da instituição (TYMOIGNE, 2009). Como exemplo desse fato, tem-se o caso da WordCom, que possuía uma participação no mercado superior a suas concorrentes, AT\&T e Sprint durante o período de fraude. Para Sadka (2006), essa empresa, aumentou sua participação no mercado para agir como se a empresa fosse verdadeiramente eficiente, tal como os demonstrativos evidenciavam.

Além desses fatores, a WordCom também relatava bons resultados operacionais durante o período de fraude. No entanto, após a descoberta da fraude, examinou-se que a empresa, na realidade, possuía uma participação no mercado abaixo da participação de seus concorrentes e os seus resultados eram, na verdade, inferiores, muito menores do que os da performance do resto da indústria (SADKA, 2006). Esse fato permite inferir que a manipulação dos resultados visou sanar problemas com um desempenho fraco da corporação.

Para testar a argumentação de que o desempenho anterior impacta na probabilidade de fraudes corporativas, elaborou-se a hipótese $\mathrm{n}^{\circ} 01$ desta pesquisa:

\section{H1: A probabilidade de ocorrência de fraudes corporativas é influenciada negativamente pelo desempenho das instituições bancárias, com defasagem temporal.}

\subsubsection{Hipótese $N^{o}$ 02: Remuneração Fixa da Gestão e Participação no Lucro}

A remuneração fixa, ou variável do agente, está interligada com o seu padrão de vida pessoal. Para Cressey (1953), a manutenção ou obtenção de um determinado padrão de vida poderá pressionar o indivíduo que ocupa uma função de confiança a fraudar.

Dessa forma, o desejo pela aquisição de um determinado nível de vida, ou a manutenção do padrão atual, poderão se tornar problemas não compartilhados quando o indivíduo perceber que "está vivendo além de seus recursos" (CRESSEY, 1953), levando-o a cometer fraudes para aumentar a sua própria remuneração e, assim, sanar seus problemas pessoais interligados ao padrão de vida.

A teoria da agência preceitua que políticas de compensação são determinadas a dar incentivos para que o agente selecione e programe ações que aumentem a riqueza dos acionistas (JENSEN; MURPHY, 1990). Nesse sentido, como tentativa de alinhar os interesses divergentes, os principais poderão optar por diferentes políticas de remuneração.

Dentre essas políticas estão a remuneração fixa, planos de remuneração com opção de ações, participação nos resultados da instituição, bônus e oportunidades de remuneração que objetivam alinhar os interesses de agentes e proprietários (MACEY, 1991).

Segundo, Byrd, Parrino e Pritsch (1998) uma remuneração composta em grande parte de um salário fixo e o investimento do gestor em capital humano específico poderão afetar o risco moral desses agentes no desempenho de suas atividades. Isso faz com que a preferência a assumir atividades mais arriscadas fique mais próxima às preferências dos credores do que às de um acionista e, dessa maneira, tornando os agentes mais conservadores em suas atividades.

Portanto, o gestor será menos propenso a executar atividades que envolvam maior nível de risco. Assim, supõem-se que a remuneração fixa influenciará no nível de propensão ao risco dos gestores, pois quanto maior a remuneração fixa menor o nível de risco assumido pelo gestor.

Ainda dentre as políticas de remuneração, existem aquelas relacionadas à lucratividade da empresa, ao implicar em uma relação positiva entre o aumento da lucratividade e a remuneração do gestor (TROY; SMITH; DOMINO, 2011; SCHRAND; ZECHMAN, 2012). Essa política tem o objetivo de incentivar o agente a buscar um melhor desempenho da empresa, o que contribui com a maximização dos interesses dos principais.

Segundo Rosen (1990) argumenta, se os agentes atuassem na empresa para atender aos 
interesses dos acionistas então eles iriam maximizar os lucros. O aumento do lucro proporciona um maior valor de dividendos para os acionistas, como também repercute no preço de suas ações. Isso, assumindo, para o preço das ações, a premissa de que o valor dos títulos reflete todas as informações relevantes disponíveis no mercado, como a lucratividade da empresa (FAMA, 1970).

Dessa forma, ao analisar a perspectiva da teoria da agência os incentivos derivados de políticas de remuneração visam contribuir com o alinhamento de interesses entre agentes e principais. Como a participação na lucratividade constitui-se em uma política de remuneração, espera-se que essa influencie o comportamento do agente nesse mesmo sentido.

No entanto, ao analisar a perspectiva da teoria do crime, observa-se as argumentações de teóricos como Macey (1991), em que os gestores, para realizar o seu objetivo de satisfação ou manutenção de um nível particular de renda, podem obtê-lo quer pelo trabalho e competência quer envolvendo-se em atividades criminosas.

Ainda segundo Macey (1991) mesmo um gestor com aversão ao risco se envolverá em atividades criminosas se, em sua opinião, os riscos associados com a atividade criminosa forem menores que os riscos associados à não realização desta atividade, incluindo nesta última o risco de perder sua ocupação por não realizar o ato criminoso.

As argumentações de Macey (1991) representam um contraponto ao estabelecido pela teoria da agência para políticas de remuneração, em especial para aquelas derivadas da participação nos resultados da instituição.

Infere-se com essas argumentações, que os agentes podem manipular os resultados da instituição com o intuito de aumentar seu incentivo financeiro derivado da participação nos lucros da instituição, com finalidade satisfazer e/ou manter seu nível particular de renda.

Dessa forma, a participação nos lucros de uma instituição influenciará positivamente a probabilidade de ocorrência de fraudes corporativas, o que leva à construção da hipótese $n^{\circ} 02$ desta pesquisa.

H2: A probabilidade de ocorrência de fraudes corporativas é influenciada positivamente pela participação no lucro da instituição bancária.

\subsection{Hipóteses da Dimensão de Oportunidade do Triângulo de Fraude}

As oportunidades resultam de circunstâncias que oferecem chances para o gestor cometer fraudes, estando diretamente interligadas aos problemas não compartilháveis do indivíduo, que na intenção de corrigi-los pode se utilizar de meios fraudulentos.

Uma pessoa que ocupa um cargo de confiança, com um problema não compartilhável, será capaz de perceber oportunidades para resolver, secretamente, esse problema. O cargo de confiança permite que o agente possua informações exclusivas sobre a posição financeira da empresa. Acesso que o permite conhecer os pontos fracos na estrutura de governança e controles internos, como também, por estar em uma posição de influência e poder, substituir os controles existentes e se envolver ou facilitar a contabilização de uma fraude (TROY; SMITH; DOMINO, 2011).

Destarte, a dimensão de oportunidade inclui uma estrutura de governança corporativa fraca e outras condições de trabalho que permitem a gestão cometer fraudes (BRAZEL; JONES; ZIMBELMAN, 2009).

Ainda, segundo Alexander e Cohen (1996), o que promove um ambiente com um número maior de oportunidades para a perpetração de fraudes é o tamanho da organização.

Assim, os itens que retratam a estrutura de governança corporativa da empresa, e o tamanho da empresa serão incluídos com intuito de se mensurar a dimensão de oportunidade 
do triângulo de Cressey (1953).

\subsubsection{Hipótese $N^{o}$ 03: Mecanismos de Governança Corporativa}

Brazel, Jones e Zimbelman (2009) utilizam mecanismos de governança corporativa como empresas de auditoria big four, número de insiders no conselho de administração e CEOs que são presidentes do conselho de administração - como meio para a mensuração da dimensão de oportunidade em seu modelo de detecção de fraudes por intermédio de medidas não financeiras. Nessa linha de raciocínio, John e Senbt (1998) afirmam que os mecanismos de governança corporativa permitem que os stakeholders de uma corporação exerçam controle sobre as atividades de insiders e dos gestores a fim de que seus interesses sejam protegidos.

Uma estrutura de governança corporativa fraca não permite que as ações dos agentes sejam monitoradas de forma adequada. Uma estrutura de governança fraca, portanto com falhas, poderá ser vislumbrada por um agente como uma oportunidade para a perpetração de fraudes corporativas.

Nessa linha de entendimento, a hipótese de $\mathrm{n}^{\mathrm{o}} 03$ foi elaborada para testar se elementos de oportunidades, mensurados pelo nível de governança corporativa, que poderão impactar na determinação da probabilidade de fraudes corporativas:

H3: A probabilidade de ocorrência de fraudes corporativas é influenciada positivamente por baixos indicadores de governança corporativa das instituições bancárias.

\subsubsection{Hipótese $N^{o}$ 04: Tamanho da Instituição}

Jensen (1986) argumenta que o crescimento da empresa aumenta o poder dos gestores através de um montante maior de recurso sob seu controle. Com o aumento da empresa, as operações tornam-se mais complexas e difíceis de monitorar, o que incorrerá em um número maior de conflito de agência. Ocorrerá também um aumento nos custos de agência, tais como custos de monitoramento dos agentes - incentivos de remuneração e mecanismos de controle despesas de vinculação contratual e perdas residuais (JENSEN; MECKLING, 1976; JENSEN, 1986; RYAN; WIGGINS, 2001).

Aumentando o tamanho da empresa, e, portanto, a complexidade de suas operações e os conflitos decorrentes da relação de agência, os gestores podem se utilizar desse ambiente para a execução de fraudes corporativas.

Nessa linha de raciocínio, os achados de Alexander e Cohen (1996) indicam que grandes empresas oferecem mais oportunidades para funcionários se engajarem em crimes corporativos do que empresas menores. Portanto, o tamanho da empresa parece influenciar de forma positiva e significativa a probabilidade de ocorrência de fraudes corporativas, propiciando assim a construção da hipótese $n^{\circ} 04$ :

H4: A probabilidade de ocorrência de fraudes corporativas é influenciada positivamente pelo tamanho das instituições bancárias.

\subsection{Hipóteses da Dimensão de Racionalização do Triângulo de Fraude}

Uma pessoa de confiança, ao definir um problema como não compartilhável, acredita que problemas não compartilháveis devem ser resolvidos de uma maneira independente, secreta e relativamente por meios seguros, ao aplicar seu conhecimento sobre informações gerais e técnicas na violação da confiança. 
O potencial violador identifica possibilidades para resolver o problema pela violação de sua posição de confiança, e define o relacionamento entre o problema e a solução ilegal como uma linguagem que o permite visualizar a violação da confiança como: a) essencialmente não criminal; b) justificada; c) parte de uma irresponsabilidade geral, para qual ele não é completamente responsável (CRESSEY, 1953). Essa linguagem, conforme o autor, é o processo de racionalização do ato.

A racionalização é um processo cognitivo em que o gestor busca classificar o ato fraudulento como aceitável e justificável (CRESSEY, 1953; MARKIN, 1979; RAHN; KROSNICK; BREUNING, 1994; SCHEUFELE, 2000).

$\mathrm{Na}$ tentativa de mensurar a dimensão de racionalização foram elaboradas hipóteses subordinadas às características demográficas dos executivos. Essas características, embora consideradas como proxies incompletas e imprecisas das estruturas cognitivas dos executivos, são tidas como válidas em função da dificuldade de se obter dados psicométricos convencionais de altos executivos (HAMBRICK, 2007).

\subsubsection{Hipótese $N^{o}$ 05: Idade dos CEOs}

O desenvolvimento moral, e de sua relação com a perpetração de atos fraudulentos, a idade do gestor foi estudada por Kelley, Ferrel e Skinner (1990), Serwinck (1992), Zahra, Priem e Rasheed (2007) e Troy, Smith e Domino (2011).

Para Kelley, Ferrel e Skinner (1990) conforme os indivíduos envelhecem, talvez eles desenvolvam uma maior compreensão do que constitui um comportamento ético, e são mais seguros em seguir esse comportamento. Nesse sentido, Serwinck (1992) afirma que empregados mais jovens tendem a ter uma visão mais liberal de situações potencialmente não éticas, enquanto, que em geral, indivíduos mais velhos tendem a ser mais conservadores que os mais jovens. Portanto, a idade está diretamente relacionada ao desenvolvimento moral do indivíduo.

Zahara, Priem e Rasheed (2007) argumentam que a necessidade de realização e progressão na carreira é mais forte nos primeiros anos de um gerente. Assim, quando gestores, os mais jovens tendem a se arriscar em atos como forma de alcançar mais rapidamente a progressão na carreira. Os gestores mais velhos tendem a ser mais analíticos em sua tomada de decisão, executando-a com maior cuidado, buscando por mais informações, realizando um diagnóstico mais preciso das informações coletadas.

Já Troy, Smith e Domino (2011) afirmam que, quanto à idade, antes de racionalizar a fraude, o gestor, dotado de um conjunto mais amplo de experiências e maturidade, refletirá sobre as repercussões da descoberta de fraudes nas demonstrações financeiras. Essas repercussões poderão ser devastadoras, dado que existem custos reputacionais individuais que o mercado impõe aos indivíduos associados a estes crimes.

$\mathrm{Na}$ mesma linha de raciocínio dos autores citados, considerando que a idade irá influenciar no desenvolvimento moral do indivíduo e em seu processo de tomada de decisão sobre a perpetração de atos fraudulentos, foi elaborada a hipótese $\mathrm{n}^{\mathrm{o}} 05$ desta pesquisa:

H5: A probabilidade de ocorrência de fraudes corporativas é influenciada negativamente pela idade dos CEOs da instituição bancária.

\subsubsection{Hipótese $N^{o}$ 06: Predominância do Gênero Feminino}

A hipótese $\mathrm{n}^{\mathrm{o}} 06$ da dimensão de racionalização trata do relacionamento entre fraudes corporativas e o gênero do executivo. Nesse sentido, pesquisas empíricas apontaram o gênero 
como um fator diferencial na percepção e perpetração de crimes.

Kelley, Ferrel e Skinner (1990), ao analisarem a relação entre o comportamento ético e as características demográficas de pesquisadores em marketing, observaram nos resultados de seu estudo que os pesquisadores do gênero feminino são mais éticos do que os do gênero masculino.

Mais especificadamente, Steffensmeier, Schwartz e Roche (2013) analisaram o efeito do gênero em crimes corporativos. Para tal, os autores utilizaram de 83 casos de fraudes corporativas envolvendo 436 réus, e subdividiram a amostra em crimes cometidos por indivíduos do gênero masculino, feminino, e crimes envolvendo esquemas com indivíduos independentemente do gênero.

A partir dos resultados encontrados, os autores afirmaram que existem boas razões para acreditar que executivos do gênero feminino podem ser mais éticos em sua tomada de decisão, são mais prováveis a honrarem as leis fundamentais dos riscos financeiros, e a evitarem riscos excessivos, tanto dentro como fora do ambiente corporativo. Ainda, os resultados indicam que gestores do gênero feminino são menos propensos a criarem ou fomentarem uma cultura organizacional criminógena.

Este resultado corrobora as afirmações de Reynolds (2006) e Zahra, Priem e Rasheed (2007). Reynolds (2006) argumenta que, como tomador de decisão mais intuitivo, o gênero feminino está mais apto a reconhecer sinais sutis dos protótipos de situações que envolvem ética e possui maior habilidade em reflexiva ou intuitivamente agir de forma eticamente aceitável.

No mesmo sentido, Zahra, Priem e Rasheed (2007) afirmam que gestores do gênero masculino estão mais propensos a aceitar o comportamento antiético para atingir seus objetivos e, ainda, que, apesar dos progressos realizados pelas mulheres o centro de poder corporativo existente é dominado pelos homens. Em face disso, a maioria dos responsáveis por atos de fraudes corporativas são do gênero masculino, pois continuam a dominar as posições de liderança corporativa.

Os estudos de Kelley, Ferrel e Skinner (1990), Reynolds (2006) e Zahra, Priem e Rasheed (2007) e Steffensmeier, Schwartz e Roche (2013) sugerem que gestores do gênero feminino são menos suscetíveis a cometerem atos fraudulentos. Portanto, presume-se que o gênero pode ser um inibidor de atos fraudulentos. Deste modo, elaborou-se a hipótese $\mathrm{n}^{\mathrm{o}} 06$ :

H6: A probabilidade de ocorrência de fraudes corporativas é influenciada negativamente pela predominância do gênero feminino na administração da instituição bancária.

\section{Metodologia da Análise Empírica}

Para a consecução do objetivo proposto, examinar se o triângulo de fraude de Cressey (1953) e a teoria de agência, em conjunto, possibilitam investigar a ocorrência de fraudes corporativas em instituições bancárias brasileiras, bem como para testar as hipóteses de pesquisa formuladas, este estudo adotou a tipologia empírica, com abordagem quantitativa.

Para isso foram dados levantados no Banco Central de 2001 (data inicial da disponibilidade das informações financeiras trimestrais - IFT) até dezembro de 2012 (data final de disponibilidade, conforme Circular 3.630, de 2013 do BACEN). Neste período foram encontradas 231 (duzentas e trinta e uma) instituições bancárias cadastradas no Brasil, o que corresponde à população da pesquisa. Destas foram analisadas apenas aquelas com registro ativo e/ou cancelado na Comissão de Valores Mobiliários - CVM, portanto, instituições bancárias de capital aberto.

Optou-se por analisar estas instituições por possuírem maior diversidade de dados 
divulgados ao mercado por meio das Informações Anuais - IANs e Formulários de Referência, documentação não obrigatória às instituições de capital fechado.

Foram identificadas 45 (quarenta e cinco) instituições bancárias, dentre as quais foi excluído o Banco BEA S/A por apresentar uma sequência de dados inferior a três anos. Portanto, foram analisadas 44 (quarenta e quatro) instituições bancárias para o período delimitado de janeiro de 2001 a dezembro de 2012.

Os dados provenientes das 44 (quarenta e quatro) instituições foram organizados pelo empilhamento de suas séries temporais, trimestralmente, o que resultou na análise de um painel desbalanceado com 2.112 (duas mil cento e doze) linhas de observações durante o período da pesquisa.

Para identificar a existência de fraudes corporativas foram utilizadas as decisões proferidas pelo Banco Central e Conselho de Recursos do Sistema Financeiro Nacional CRSFN, em processos administrativos punitivos. O Banco Central, em seu papel punitivo, promulgará as decisões de primeira instância. Já o Conselho de Recursos do Sistema Financeiro Nacional - CRSFN, julgará esses processos em segunda instância. Destaque-se que o CRSFN é a última instância julgadora para os processos administrativos punitivos. Frisa-se que esses processos administrativos estavam finalizados, e sua inclusão na base dados das pesquisas respeitou a data de emissão das decisões proferidas pelo Banco Central e pelo CRSFN.

Das 44 (quarenta e quatro) instituições analisadas, identificaram-se 27 (vinte e sete) com processos administrativos punitivos finalizados, correspondendo a $61,36 \%$ do total. As entidades que não foram identificadas dentro do grupo de empresas com processo compõem a amostra de controle, o que permitirá identificar os padrões de diferença entre os dois grupos de instituições (com e sem processos). Foram coletados 123 (cento e vinte e três) processos administrativos punitivos já finalizados para as instituições selecionadas.

Ressalte-se que para a classificação dos processos foi observado o conceito de fraude corporativa: aquela cometida por ou contra uma corporação (SINGLENTON; SINGLENTON, 2010), o que permite, portanto, a análise conjunta dos tipos de conflitos de agência existentes dentro da corporação, como problemas entre acionistas e a direção, e acionistas e detentores da dívida (JOHN; SENBET, 1998).

\subsection{Modelagem Econométrica}

Para este estudo optou-se por uma descrição maior da variável dependente, considerando não somente a presença ou a ausência do atributo, mas também a maior qualificação do mesmo. Face a esta opção, verifica-se que o modelo logit binário não permite analisar os diferentes cursos que resultam da ação de fiscalização efetuada pelo Banco Central do Brasil, deixando de incluir as instituições que foram investigadas, processadas administrativamente e inocentadas. Destaque-se, que esse tipo de instituição contempla uma característica distinta, pois não pode ser considerada como uma instituição ilesa, tão pouco como fraudadora. Nessa situação, carece de uma análise diferenciada.

Dessa maneira, a variável dependente possui respostas policotômicas - também conhecido como primeiras escolhas ou escolhas discretas - que podem assumir valores distintos e não ordenados. Por conseguinte, a relação funcional entre fraudes corporativas e variáveis independentes, a serem posteriormente apresentadas, foi apurada pela aplicação de uma regressão logit multinomial. Uma variante do modelo logit, bem como do probit, que trata da variável dependente policotômica e permite a análise simultânea dos atributos da variável dependente.

Destaque-se que em função do conjunto de dados coletados, organizados em um empilhamento de cortes transversais e longitudinais, torna-se necessário refletir sobre o 
emprego de uma metodologia apropriada do modelo logit multinomial, se aplicado em sua forma tradicional ou com efeitos aleatórios.

\subsubsection{Modelos Logit Multinomiais Tradicionais e com Efeito Aleatório}

Os modelos logit multinomias são não lineares, e permitem captar a probabilidades de categorias de um evento ocorrer sobre outras categorias. Nas palavras de Hilbe (2009) esse tipo de modelagem é uma extensão dos modelos lineares generalizados, permitindo uma estimação de categorias de resposta não ordenadas.

Dessa forma, um banco $i=1, \ldots, n$, poderá ser classificado em uma das j-ésimas categorias. Para este estudo foram definidas três categorias:

- $\quad j=1$ representa as instituições bancárias sem processos administrativos punitivos;

- $j=2$, para instituições bancárias com processos administrativos punitivos e não condenadas; e

- $j=3$ corresponde as instituições bancárias com processos administrativos punitivos e condenadas pelo Banco Central ou CRSFN.

A probabilidade de que uma instituição está em uma determinada categoria $j$, é dada pela seguinte função:

$$
\operatorname{Pr}\left(Y_{t}=j \mid X_{i, t}\right)=\frac{e^{\beta_{j} X_{i, t}+\alpha_{j}}}{1+\sum_{j=1}^{3} e^{\beta_{j} X_{i, t}+\alpha_{j}}}, \operatorname{paraj}=1, \ldots 3(1)
$$

Como categoria de base/referência serão utilizadas as instituições sem processos administrativos punitivos $(\mathrm{Y}=1)$, a fim de fornecer a identificação para o modelo multinomial logit.

Onde $X_{i, t}$ é o vetor dos regressores das dimensões e $\square$ é o vetor dos parâmetros a serem estimados, $\mathrm{Y}$ corresponde à variável regressanda e $\propto_{j}$ é o efeito da alternativa $\mathrm{j}$. $\mathrm{O}$ vetor de parâmetro $\beta_{1}$ mensura o efeito de uma alteração nas variáveis independentes $X_{i, t}$, a serem posteriormente indicadas na seção 3.1.2, na probabilidade de uma instituição bancária ser classificada como detentora de indícios de fraudes corporativas, em relação à probabilidade de ser classificada como instituição sem processos administrativos. Já o vetor de parâmetro $\beta_{2}$ mensura o efeito de uma alteração nas variáveis independentes $X_{i, t}$ sobre a probabilidade de uma instituição ser classificada como possuindo fraudes corporativas, em relação à probabilidade de ser classificada como sem processos administrativos punitivos.

O modelo tradicional está limitado pela hipótese das alternativas irrelevantes (IIA), na qual a probabilidade da ocorrência de uma categoria não influirá na probabilidade de ocorrência de outra categoria. Ou seja, a escolha de um nível de alternativa sobre outra não é afetada pela existência de outras escolhas ou níveis (HILBE, 2009; GRILLI; RAMPICHINI, 2007). Assim, as probabilidades não dependem das alternativas que estão disponíveis. Neste sentido, essas alternativas são irrelevantes. Tal fato significa que a adição ou exclusão de alternativas não afetará as probabilidades das alternativas remanescentes (LONG; FREESE, 2006).

Conforme afirmam Skrondal e Rabe-Hesketh (2003), o modelo multinomial tradicional tem sido apontado na literatura por envolver uma suposição questionável do pressuposto da independência, conhecido como Independência das Alternativas Irrelevantes (IIA). Os dados provenientes desses modelos são frequentemente de natureza multinível, onde as unidades são aproximadas em clusters como, por exemplo, dados em painéis, em que níveis como empresas, regiões ou países podem ser considerados.

Dessa forma, a obrigatoriedade do pressuposto da IIA é combinada a um design multinível em função de uma dependência adicional, entre unidades dentro de clusters, que é tipicamente induzida por uma heterogeneidade não observada entre os clusters. 
Segundo Skrondal e Rabe-Hesketh (2004) pode-se distinguir dois tipos de consequências da heterogeneidade não observada. A dependência dentro do agrupamento e a sobre dispersão. Essas consequências resultam em inferências incorretas se não apropriadamente tratadas. Uma maneira de tratar essa heterogeneidade é a inclusão de um efeito aleatório no modelo de regressão. Portanto, modelos multinomiais logit com efeito aleatório fazem-se úteis para a prevenção de problemas de heterogeneidade não observada.

O modelo logit multinomial em painel e com efeito aleatório compõe uma ampla classe de modelos logit mistos, que por sua vez pertencem a uma categoria uma classe altamente flexível de modelos de aproximação de qualquer formulação de utilidade aleatória (TRAIN, 2003; HAAN; UHLENDORFF, 2006).

Frees (2004) argumenta que observações repetidas de um indivíduo tendem a ser similares. No caso de escolhas categóricas, isto significa que os indivíduos tendem a fazer as mesmas escolhas de uma observação para a próxima. Dessa forma, o preditor linear, representado por $V_{i t, j}, j=1 ; j=2 ; e j=3$, de um modelo logit multinomial com efeito aleatório, pode ser definido como:

$$
V_{i t, j}=\beta x_{i t, j}+\alpha_{i}(2)
$$

Na equação 2, $\alpha_{i}$ representa o termo de heterogeneidade que é específico, onde o efeito varia por indivíduo $(i)$ e alternativa $(j)$, no entanto é comum sobre o tempo $(t)$. Com esta especificação para o componente sistemático, a probabilidade condicional (na heterogeneidade) para a empresa $i$ th no tempo $t$ alocado na alternativa $j$ th é retratada na equação abaixo:

$\operatorname{Pr}\left(Y_{t}=j \mid X_{i, t}, \alpha_{i}\right)=\frac{e^{\beta_{j} X_{i, t}+\alpha_{i j}}}{1+\sum_{j=1}^{3} e^{\beta_{j} X_{i, t+\alpha_{i j}}}}$, para $=1, \ldots 3(3)$

Conforme Haynes, Wester e Spallek (2005), os efeito aleatório dados por $\alpha_{i}=$ $\left(\alpha_{i 1}, \ldots \alpha_{i c}\right)$ capturam o efeito individual não observado, com distribuição multivariada normal com média zero e matriz de variância-covariância $\sum$. Segundo Skrondal e Habe-Hesketh (2004), esses efeitos são assumidos como correlacionados.

Haan e Uhlerdorff (2006) asseveram, em função de as probabilidades de escolha serem condicionais a $\alpha_{i}$, que é necessário integrar a distribuição da heterogeneidade não observada. Assim, a verossimilhança para o modelo logit multinomial com efeito aleatório é dado por:

$$
L=\prod_{i=1}^{N} \int_{-\infty}^{\infty} \prod_{t=1}^{T} \prod_{j=1}^{J}\left\{\frac{e^{\beta_{j} X_{i, t}+\alpha_{i j}}}{\sum_{k=1}^{J} e^{\beta_{j} X_{i, t+\alpha_{i j}}}}\right\}^{d_{i j t}} f(\alpha) d \alpha(4)
$$

Sendo $d_{i j t}=1$, se a empresa $\mathrm{i}$ for alocada na alternativa $\mathrm{J}$ no período $\mathrm{t}$, e 0 caso contrário. $\mathrm{O}$ vetor de coeficientes e o termo que representa a heterogeneidade não observada são tidos como zero para a categoria base, a fim de garantir a identificação do modelo. Por fim, assumese que a heterogeneidade não observada, $\alpha$, deve ser independente das variáveis explicativas, $x_{i t}$.

A comparação entre os dois tipos de modelos logísticos multinomiais, tradicional ou com efeito aleatório, foi realizada mediante a aplicação do teste de Cramer e Ridder (1991). Esse teste, após a mensuração do modelo logit multinomial tradicional verifica se este modelo pode ser utilizado com um pooled simples.

O teste de Cramer e Ridder (1991) assume um modelo logit multinomial com (S+1) 
estados, e dois estados/níveis que são candidatos a pooling, $s_{1}$ e $s_{2}$. A hipótese nula pressupõe que $s_{1}$ e $s_{2}$ possuem os mesmos coeficientes regressores, exceto o efeito, isto é:

$$
\beta_{s_{1}}=\beta_{s_{2}}=\beta_{s}(5)
$$

Dessa maneira, para os modelos em que o teste de Cramer e Ridder (1991) indicou que o modelo logit multinomial foi passível de ser analisado, a hipótese das alternativas irrelevantes foi testada. Essa hipótese (IIA) assegura se a utilização do modelo multinomial é apropriado. Assim, foram aplicados o teste de Hausman-MacFadden (1984), o teste de Small-Hsiao (1985) e, alternativamente, o Suest-base Hausman, para verificação da independência das alternativas irrelevantes, e, por conseguinte, da suposição de independência entre os termos de erro.

Para os modelos em que o teste de Cramer e Ridder (1991) indicou que um pooled simples não foi a melhor alternativa, foi empregado um modelo logit multinomial com efeito aleatório. Para este modelo utilizou-se do programa Stata, versão 13, que possibilita mensurar os modelos logit multinomiais com efeito aleatório, por intermédio do comando gsem.

Uma comparação adicional entre os modelos logit multinomiais, tradicional e com efeito aleatório, foi realizada. Essa comparação foi obtida pela análise dos critérios de informação - Akaike Information Criterion - AIC, Bayesian Information Criterion - BIC, e pelo Likelihood-ratio test, com intuito de garantir a escolha do modelo que melhor se ajusta aos dados.

Além desses testes, para interpretação dos coeficientes dos modelos logit multinomiais, tradicional e com efeito aleatório, foi utilizada a razão de risco relativo (rrr), que é a razão entre a probabilidade de cada categoria com os resultados da categoria de referência. Esse procedimento facilita a interpretação dos coeficientes e a análise da contribuição de cada variável para a detecção de fraudes corporativas ou indícios de fraudes corporativas comparadas com a categoria de referência: instituições bancárias sem processos administrativos punitivos.

\subsubsection{Variáveis Independentes}

O conjunto de variáveis independentes, $X_{i, t}$, foi definido, em sua maioria, com o auxílio da literatura da teoria da agência, economia do crime e pesquisas empíricas sobre fraudes corporativas e/ou contábeis. A descrição dessas variáveis, fontes de coleta e pesquisa, juntamente com as variáveis de controle utilizadas, estão apresentadas no Quadro 1.

Quadro 1 - Variáveis utilizadas

\begin{tabular}{|r|l|c|l|l|}
\hline \multicolumn{5}{|c|}{ DIMENSÃO DO TRIÂNGULO DE FRAUDE: PRESSÃO } \\
\hline $\mathbf{N}^{\mathbf{0}}$ & Variável & $\begin{array}{c}\text { Hipótese } \\
\text { de } \\
\text { pesquisa }\end{array}$ & Descrição e Fonte de Coleta & Autores \\
\hline 1 & RIF_AT L1 & H1 & $\begin{array}{l}\text { Receita de Intermediação } \\
\text { financeira dividida pelo Ativo total } \\
\text { em t-1. Fonte: IFTs. }\end{array}$ & $\begin{array}{l}\text { Alexander e Cohen (1996); Brazel, Jones e } \\
\text { Zimbelman (2009); Matousek et al (2014) }\end{array}$ \\
\hline 2 & VAR_LL_L1 & H1 & $\begin{array}{l}\text { Variação do Lucro Líquido em t-1. } \\
\text { Fonte: IFTs. }\end{array}$ & $\begin{array}{l}\text { Alexander e Cohen (1996); Crutcheley, } \\
\text { Jensen e Marshal (2007 }\end{array}$ \\
\hline & & & $\begin{array}{l}\text { Grau de participação no mercado: } \\
\text { Resultado Operacional do banco i } \\
\text { dividido pelo Resultado } \\
\text { Operacional do banco líder de } \\
\text { mercado, em t-1. Fonte: IFTs. }\end{array}$ & $\begin{array}{l}\text { Gartner (2010); Sadka (2006) e Tymoigne } \\
\text { (2009) }\end{array}$ \\
\hline
\end{tabular}

Continua 


\begin{tabular}{|c|c|c|c|c|}
\hline \multicolumn{5}{|c|}{ DIMENSÃO DO TRIÂNGULO DE FRAUDE: PRESSÃO } \\
\hline 4 & ROA L1 & $\mathrm{H} 1$ & $\begin{array}{l}\text { Lucro operacional dividido pelo } \\
\text { ativo total em t-1. Fonte: IFTs. }\end{array}$ & $\begin{array}{l}\text { Berger et al (2005); Brazel, Jones e } \\
\text { Zimbelman (2009); Berger, Hasan e Zhou } \\
\text { (2010); Wang, Winton e You (2010); Troy, } \\
\text { Smith e Domino (2011); Wang (2011); e } \\
\text { Cogneau e Hübner (2014). }\end{array}$ \\
\hline 5 & ROE L1 & $\mathrm{H} 1$ & $\begin{array}{l}\text { Lucro líquido dividido pelo } \\
\text { patrimônio líquido em t-1. Fonte: } \\
\text { IFTs. } \\
\end{array}$ & $\begin{array}{l}\text { Berger (1995) Boni, Hasan e Wachtel } \\
\text { (2005); Matousek et al (2014). }\end{array}$ \\
\hline 6 & PART LL & $\mathrm{H} 2$ & $\begin{array}{l}\text { Dummy para indicar se os diretores } \\
\text { recebem participação nos lucros da } \\
\text { empresa. Fonte: IANs e } \\
\text { Formulários de Referência. }\end{array}$ & $\begin{array}{l}\text { Crutchley, Jensen e Marshall (2007); } \\
\text { Erickson, Hanlon e Maydew (2006); Wang, } \\
\text { Winton e Yu (2010); Troy, Smith e Domino } \\
\text { (2011). }\end{array}$ \\
\hline 7 & LN_REM & $\mathrm{H} 2$ & $\begin{array}{l}\text { Logaritmo natural do valor da } \\
\text { remuneração trimestral. Fonte: } \\
\text { Atas do conselho de administração, } \\
\text { IANs e Formulários de Referência. }\end{array}$ & $\begin{array}{l}\text { Crutcheley, Jensen e Marshall (2007); } \\
\text { Erickson, Hanlon e Maydew (2006) Wang, } \\
\text { Winton e Yu (2010); Troy, Smith e Domino } \\
\text { (2011) }\end{array}$ \\
\hline \multicolumn{5}{|c|}{ DIMENSÃO DO TRIÂNGULO DE FRAUDE: OPORTUNIDADE } \\
\hline $\mathrm{N}^{\mathbf{0}}$ & Códigos & $\begin{array}{c}\text { Hipótese } \\
\text { de } \\
\text { pesquisa }\end{array}$ & Descrição e Fonte de Coleta & Autores \\
\hline 8 & MCI2 & $\mathrm{H} 3$ & \begin{tabular}{|lrrr} 
Número & de & \multicolumn{2}{r}{ membros } \\
independentes & no conselho & de \\
administração & elevado & ao \\
quadrado. Fonte: IANs & e \\
Formulários de Referência. & \\
\end{tabular} & $\begin{array}{l}\text { Crutchley, Jensen e Marshall (2007); Troy, } \\
\text { Smith e Domino (2011); Beasley (1996); } \\
\text { Wang et al (2013). }\end{array}$ \\
\hline 9 & TCA2 & $\mathrm{H} 3$ & $\begin{array}{l}\text { Número de membros do conselho } \\
\text { de administração elevado ao } \\
\text { quadrado. Fonte: IANs e } \\
\text { Formulários de Referência. } \\
\end{array}$ & $\begin{array}{l}\text { Crutchley, Jensen e Marshall (2007); Troy, } \\
\text { Smith e Domino (2011); Wang et al (2013). }\end{array}$ \\
\hline 10 & TCF2 & $\mathrm{H} 3$ & $\begin{array}{l}\text { Número de membros do conselho } \\
\text { fiscal elevado ao quadrado. Fonte: } \\
\text { IANs e Formulários de Referência. } \\
\end{array}$ & Trapp (2009) \\
\hline 11 & CEO ROT & H3 & $\begin{array}{l}\text { Dummy para mudança de um CEO. } \\
\text { Fonte: IANs e Formulários de } \\
\text { Referência. }\end{array}$ & John e Senbet (1998). \\
\hline 12 & LN TAM DIR & $\mathrm{H} 3$ & $\begin{array}{l}\text { Logaritmo natural do número de } \\
\text { diretores da empresa }\end{array}$ & Elaboração própria. \\
\hline 13 & SELO_GOV & $\mathrm{H} 3$ & $\begin{array}{l}\text { Dummy para empresas que estão } \\
\text { listadas nos segmentos de } \\
\text { governança corporativa da BM\&F } \\
\text { Bovespa. Fonte: Boletim Diário de } \\
\text { Notícias da Bovespa. }\end{array}$ & Bovespa (2014). \\
\hline 14 & BIG_FIVE & $\mathrm{H} 3$ & $\begin{array}{l}\text { Dummy para indicar se a empresa } \\
\text { de auditoria é uma big five ou não. } \\
\text { Fonte: Relatórios de auditoria, } \\
\text { BACEN. }\end{array}$ & $\begin{array}{l}\text { Lennox e Pittman (2010); Brazel, Jones e } \\
\text { Zimbelman (2009). }\end{array}$ \\
\hline 15 & LN_ATIVO_TOTAL & $\mathrm{H} 4$ & $\begin{array}{l}\text { Log natural do ativo total. Fonte: } \\
\text { IFTs. }\end{array}$ & $\begin{array}{l}\text { Wang (2011); Troy, Smith e Domino (2011) } \\
\text { e Brazel, Jones e Zimbelman (2009). }\end{array}$ \\
\hline \multicolumn{5}{|c|}{ DIMENSÃO DO TRIÂNGULO DE FRAUDE: RACIONALIZAÇÃO } \\
\hline $\mathbf{N}^{\mathbf{0}}$ & Códigos & $\begin{array}{c}\text { Hipótese } \\
\text { de } \\
\text { pesquisa }\end{array}$ & Descrição e Fonte de Coleta & Autores \\
\hline 16 & IDADE & $\mathrm{H} 5$ & $\begin{array}{l}\text { Idade do CEO. Fonte: IANs e } \\
\text { Formulários de Referência. }\end{array}$ & $\begin{array}{l}\text { Kelley, Ferrel e Skinner (1990); Zahra, } \\
\text { Priem e Rasheed (2007); Troy, Smith e } \\
\text { Domino (2011). }\end{array}$ \\
\hline 17 & PRED MUL CF & H6 & $\begin{array}{l}\text { Percentual do número de diretores } \\
\text { do gênero feminino sobre o número } \\
\text { total de membros do conselho } \\
\text { fiscal. Fonte: IANs e Formulários } \\
\text { de Referência. }\end{array}$ & $\begin{array}{l}\text { Kelley, Ferrel e Skinner (1990); Reynolds } \\
\text { (2006); Zhara, Priem e Skinner (2007) e } \\
\text { Steffensmeier, Schwartz e Roche (2013). }\end{array}$ \\
\hline
\end{tabular}

Continua 


\begin{tabular}{|c|c|c|c|c|}
\hline \multicolumn{5}{|c|}{ DIMENSÃO DO TRIÂNGULO DE FRAUDE: RACIONALIZAÇÃO } \\
\hline 18 & PRED MUL CA & H6 & $\begin{array}{l}\text { Percentual do número de diretores } \\
\text { do gênero feminino sobre o número } \\
\text { total de membros do conselho de } \\
\text { administração. Fonte: IANs e } \\
\text { Formulários de Referência. }\end{array}$ & $\begin{array}{l}\text { Kelley, Ferrel e Skinner (1990); Reynolds } \\
\text { (2006); Zhara, Priem e Skinner (2007) e } \\
\text { Steffensmeier, Schwartz e Roche (2013). }\end{array}$ \\
\hline 19 & PRED MUL C DIR & H6 & $\begin{array}{l}\text { Percentual do número de diretores } \\
\text { do gênero feminino sobre o número } \\
\text { total de membros da diretoria } \\
\text { executiva. Fonte: IANs e } \\
\text { Formulários de Referência. }\end{array}$ & $\begin{array}{l}\text { Kelley, Ferrel e Skinner (1990); Reynolds } \\
\text { (2006); Zhara, Priem e Skinner (2007) e } \\
\text { Steffensmeier, Schwartz e Roche (2013). }\end{array}$ \\
\hline \multicolumn{5}{|c|}{ VARIÁVEIS DE CONTROLE } \\
\hline $\mathbf{N}^{\mathbf{0}}$ & Códigos & \multicolumn{2}{|c|}{ Descrição e Fonte de Coleta } & Autores \\
\hline 20 & TIP BCO & \multicolumn{2}{|c|}{$\begin{array}{l}\text { Dummy para bancos múltiplos e comerciais. } \\
\text { Fonte: Dados cadastrais, BACEN. }\end{array}$} & Elaboracão própria. \\
\hline 21 & CONVERG & \multicolumn{2}{|c|}{$\begin{array}{l}\text { Dummy para o período de convergência às } \\
\text { normas internacionais de contabilidade. }\end{array}$} & $\begin{array}{l}\text { Elaborada a partir da Resolução BACEN n }{ }^{\circ} \\
\text { 3.786/2009. }\end{array}$ \\
\hline 22 & ESTAT & \multicolumn{2}{|c|}{$\begin{array}{l}\text { Dummy para bancos de controle estatal (governo } \\
\text { federal, estadual ou municipal). Fonte: IANs e } \\
\text { Formulários de Referência. }\end{array}$} & Berger et al (2005) e Silva (2004). \\
\hline 23 & CRISE & \multicolumn{2}{|c|}{$\begin{array}{l}\text { Dummy para indicar o período da crise subprime } \\
\text { (Julho de } 2007 \text { a abril de 2009). }\end{array}$} & Maciel et al (2012). \\
\hline
\end{tabular}

Notas: IANs = Formulário de Informações Anuais; IFT = Informações Financeiras Trimestrais

Fonte: Elaborado pela autora a partir de pesquisas empíricas.

As variáveis apresentadas no Quadro 1 foram utilizadas para testar as hipóteses elaboradas na seção de fundamentação teórica; cada qual com um modelo econométrico apropriado. Optou-se pela estimação individual das hipóteses para fins de não ocorrer em problemas de multicolinearidade, já que ao total são examinadas 23 variáveis explicativas. Decisão esta tomada por autores como Crutcheley, Jensen e Marshall (2007) e Lou e Wang (2009), em pesquisas sobre fraudes.

Saliente-se que em face do período de pesquisa, janeiro de 2001 a dezembro de 2012 , as variáveis derivadas dos demonstrativos financeiros e a remuneração fixa da gestão, foram corrigidas monetariamente. Para tal, foi utilizado o índice de atualização monetária, IGP-DI, calculado mensalmente pela Fundação Getúlio Vargas - FGV. Esse procedimento permitirá analisar o impacto dessas variáveis em um mesmo plano de tempo, ou seja, sem a influência da inflação.

Destaque-se que as empresas de auditoria antes denominadas como big five, atualmente são denominadas como big four: Delloite, KPMG, Ernst \& Young e PriceWaterHouseCoopers. Essa modificação ocorreu em função da falência da empresa Artur Andersen em 2002.

Para essa pesquisa será considerado o termo big five, isso porque no período que abrange a pesquisa, de janeiro de 2001 a dezembro de 2012, a empresa de auditoria Arthur Andersen ainda era considerada como uma big five. Dessa forma, considerou-se o mesmo tratamento dado por Lennox e Pittman (2010) para analisar o efeito das empresas de auditoria - big five ou big four - na detecção de fraudes corporativas.

Para os modelos ainda foram definidas quatro variáveis de controle: tipo de banco, convergência às normas internacionais de contabilidade, controle estatal e crise subprime.

A primeira variável de controle permite qualificar o tipo de instituição bancária segundo a classificação de sua atividade pelo Banco Central do Brasil, se banco múltiplo ou comercial. A variável convergência foi empregada com a finalidade de distinguir o período em que a conversão às normas internacionais de contabilidade passou a vigorar, conforme Resolução do BACEN no 3.786 de 2009. Essa variável de controle, convergência às normas internacionais, somente será usada nos modelos econométricos que possuem, dentre suas variáveis independentes aquelas oriundas dos demonstrativos contábeis. Conforme informações do 
Banco Central, as normas contábeis estabelecidas pelo Conselho Monetário Nacional e pelo Banco Central do Brasil consubstanciadas no COSIF - Plano Contábil das Instituições do Sistema Financeiro Nacional, apresentam divergências em relação as normas internacionais de contabilidade emitidas pelo IASB - International Accounting Standard Board, representando, portanto, uma convergência parcial às normas internacionais de contabilidade.

Para o efeito do controle e propriedade das instituições bancárias considerou-se incluir as variáveis que identificam se o controle é estatal ou estrangeiro. Esses dois tipos de categorias, possuem características diferentes das demais instituições bancárias. Os bancos estrangeiros precisam lidar com ambientes e regulamentações diversas, as regulamentações do seu país de origem e as da instituição estrangeira. Enquanto os bancos estatais podem operar com subsídios governamentais, além de possuírem uma governança mais complexa, em função da presença de mais um agente: o político (SILVA, 2004).

No entanto, nesse trabalho, não foi diferenciado o controle estrangeiro, visto que para o setor bancário $87,38 \%$ dos ativos totais em 2012, são de bancos com origem de capital nacional. Além do número limitado de instituições bancárias com controle estrangeiro, correspondendo a 6 das 44 instituições analisadas.

A quarta variável de controle foi incluída para analisar o efeito da crise do subprime. Assim, a variável indicará o período de crise ocorrido meados de 2007 a abril de 2009 (MACIEL et al, 2012).

Ressalte-se que para a dimensão de racionalização, em função da natureza das variáveis de interesse para essa dimensão, as quais representam as características demográficas dos gestores, foi incluída como variável de controle o logaritmo natural do ativo total. Esse procedimento foi realizado na tentativa de se controlar qualquer efeito de tamanho existente entre essas características dos gestores.

\section{Análise Empírica}

Para melhor apresentação dos resultados obtidos, este tópico foi subdividido segundo as hipóteses elaboradas para mensurar as dimensões do triângulo de fraudes, a saber: pressão, oportunidade e racionalização.

\subsection{Resultados das Hipótese da Dimensão de Pressão do Triângulo de Fraude}

Esta dimensão relaciona-se a pressões, de natureza interna ou externa, oriundas de problemas financeiros não compartilhados pelo fraudador. Tais pressões exercem sobre o indivíduo um desejo de obter um resultado específico para solucionar esse problema, que pode ocorrer pela violação da confiança financeira. (CRESSEY, 1953). Esse desejo pode estar relacionado, de alguma forma, com a busca pela manutenção de status de comportamento do fraudador.

Neste item apresentam-se os resultados da mensuração dos modelos individuais criados para testar as hipóteses da dimensão de pressão do triângulo de fraude.

\subsubsection{Dimensão de Pressão: Hipótese $n^{0} 01$}

A hipótese $\mathrm{n}^{\mathrm{o}} 01$ testa a relação entre a probabilidade de ocorrência de fraudes corporativas e o desempenho das instituições bancárias com defasagem temporal. Os resultados obtidos estão evidenciados na Tabela 1 .

$\mathrm{Na}$ Tabela 1, apresentam-se tanto o modelo logit multinomial tradicional, quanto o modelo logit multinomial com efeito aleatório. Os resultados do teste de Cramer e Ridder (1991) indicam que, exceto para as alternativas 01 e 02 , os agrupamentos entre as alternativas 
não podem ser realizados ao nível de significância de $1 \%$.

Tabela 1 - Relação entre desempenho anterior e fraudes corporativas: Hipótese $\mathbf{n}^{0} 01$

\begin{tabular}{|c|c|c|c|c|c|c|c|c|}
\hline \multirow[b]{4}{*}{ Variáveis } & \multicolumn{4}{|c|}{ Multinomial Logit Tradicional } & \multicolumn{4}{|c|}{ Multinomial Logit com Efeito Aleatório } \\
\hline & \multicolumn{4}{|c|}{ Hipótese n⿳0 01} & \multicolumn{4}{|c|}{ Hipótese $n^{0} 01$} \\
\hline & \multicolumn{2}{|c|}{ Proc. Sem Cond. } & \multicolumn{2}{|c|}{ Proc. Com Cond. } & \multicolumn{2}{|c|}{ Proc. Sem Cond. } & \multicolumn{2}{|c|}{ Proc. Com Cond. } \\
\hline & Coef. & $\begin{array}{l}\text { Odds } \\
\text { Ratio }\end{array}$ & Coef. & $\begin{array}{l}\text { Odds } \\
\text { Ratio }\end{array}$ & Coef. & \begin{tabular}{|l|} 
Odds \\
Ratio
\end{tabular} & Coef. & $\begin{array}{l}\text { Odds } \\
\text { Ratio }\end{array}$ \\
\hline \multirow[t]{2}{*}{ rif_at_L1 } & $-0,2901$ & 0,7482 & 9,5553 & 14119,1507 & $-0,1509$ & 0,8599 & 11,2744 & 78776,214 \\
\hline & $(7,0833)$ & $(5,2995)$ & $(6,9885)$ & $(98672,31)$ & $(7,4686)$ & $(6,4224)$ & $(7,2545)$ & $(571480,3)$ \\
\hline \multirow[t]{2}{*}{ var_11_L1 } & 0,0018 & 1,0018 & 0,0035 & 1,0036 & 0,0021 & 1,0021 & 0,0048 & 1,0048 \\
\hline & $(0,0022)$ & $(0,0022)$ & $(0,0025)$ & $(0,0026)$ & $(0,0022)$ & $(0,0023)$ & $(0,0031)$ & $(0,0031)$ \\
\hline \multirow[t]{2}{*}{ roe_L1 } & $1,9608^{* * *}$ & $7,1048 * * *$ & $2,3195^{* * *}$ & $10,1707 * * *$ & $2,0677 * * *$ & $7,9069 * * *$ & 1,9014 & 6,6952 \\
\hline & $(0,6323)$ & $(4,4922)$ & $(0,5054)$ & $(5,1400)$ & $(0,7860)$ & $(6,2147)$ & $(1,2880)$ & $(8,6233)$ \\
\hline \multirow[t]{2}{*}{ roa_L1 } & $-1,8981$ & 0,1498 & $-20,0079 * *$ & $0,0000^{* *}$ & $-0,3993$ & 0,6708 & $-24,0266^{* *}$ & $0,0000 * *$ \\
\hline & $(10,2572)$ & $(1,5370)$ & $(8,1786)$ & 0,0000 & $(10,2169)$ & $(6,8535)$ & $(10,6089)$ & 0,0000 \\
\hline \multirow[t]{2}{*}{ part_mer_L1 } & 0,3585 & 1,4311 & 0,6344 & 1,8859 & 0,2321 & 1,2612 & 0,9079 & 2,4792 \\
\hline & $(1,4424)$ & $(2,0643)$ & $(0,4958)$ & $(0,9349)$ & $(1,5282)$ & $(1,9274)$ & $(0,6498)$ & $(1,6111)$ \\
\hline \multirow[t]{2}{*}{ tip_bco } & 0,9492 & 2,5836 & $-0,7263$ & 0,4837 & 1,0703 & 2,9161 & $-1,1451$ & 0,3182 \\
\hline & $(0,9039)$ & $(2,3352)$ & $(0,5287)$ & $(0,2557)$ & $(1,0627)$ & $(3,0989)$ & $(1,2284)$ & $(0,3909)$ \\
\hline \multirow[t]{2}{*}{ converg } & $-2,2110 * *$ & $0,1096 * *$ & $-1,3632 * *$ & $0,2558 * *$ & $-2,2372 * *$ & $0,1068 * *$ & $-1,4552 * *$ & $0,2333 * *$ \\
\hline & $(1,0274)$ & $(0,1126)$ & $(0,6357)$ & $(0,1626)$ & $(1,0280)$ & $(0,1097)$ & $(0,6476)$ & $(0,1511)$ \\
\hline \multirow[t]{2}{*}{ estat } & 0,1187 & 1,1261 & $1,0753 * * *$ & $2,9309^{* * *}$ & 0,039 & 1,0398 & 0,9163 & 2,4999 \\
\hline & $(0,4595)$ & $(0,5174)$ & $(0,4157)$ & $(1,2184)$ & $(0,5262)$ & $(0,5472)$ & $(0,7816)$ & $(1,9540)$ \\
\hline \multirow[t]{2}{*}{ Crise } & $-0,5422$ & 0,5815 & $-1,3435^{* *}$ & $0,2609 * *$ & $-0,5742$ & 0,5632 & $-1,4429 * *$ & $0,2362 * *$ \\
\hline & $(0,4930)$ & $(0,2867)$ & $(0,6252)$ & $(0,1631)$ & $(0,4951)$ & $(0,2788)$ & $(0,6411)$ & $(0,1515)$ \\
\hline \multirow[t]{2}{*}{ M1[i] } & & & & & 1 & 2,7183 & $2,3701 * *$ & $10,6989^{* *}$ \\
\hline & & & & & 0 & 0 & $(1,0067)$ & $(10,7701)$ \\
\hline \multirow[t]{2}{*}{ Constant } & $-4,7883 * * *$ & $0,0083 * * *$ & $-4,0053 * * *$ & $0,0182 * * *$ & $-5,0803 * * *$ & $0,0062 * * *$ & $-4,4962 * * *$ & $0,0112 * * *$ \\
\hline & $(1,0328)$ & $(0,0086)$ & $(0,7204)$ & $(0,0131)$ & $(1,2143)$ & $(0,0076)$ & $(1,3695)$ & $(0,0153)$ \\
\hline \multicolumn{9}{|l|}{$\operatorname{var}(\mathrm{M} 1[\mathrm{i}])$} \\
\hline \multirow[t]{2}{*}{ Constant } & & & & & 0,3913 & 1,4789 & & \\
\hline & & & & & $(0,3318)$ & $(0,4907)$ & & \\
\hline Obs. & \multicolumn{4}{|c|}{$\frac{1}{1814}$} & \multicolumn{4}{|c|}{1814} \\
\hline $\begin{array}{l}\text { Log } \\
\text { likelihood }\end{array}$ & \multicolumn{4}{|c|}{$-333,100$} & \multicolumn{4}{|c|}{$-319,700$} \\
\hline AIC & \multicolumn{4}{|c|}{706,219} & & & 421 & \\
\hline $\mathrm{BIC}$ & & 816 & 285 & & & & 493 & \\
\hline LR test & 26,800 & & & Teste de & Cramer e I & $\operatorname{der}(1991)$ & & \\
\hline $\begin{array}{l}\text { P-valor LR } \\
\text { test }\end{array}$ & 0,0000 & $\begin{array}{r}\mathrm{P}>\mathrm{chi} 2 \\
01: 02\end{array}$ & 0,038 & $\begin{array}{r}\mathrm{P}>\mathrm{c} \\
01\end{array}$ & & 0000 & $\begin{array}{c}>\operatorname{chi} 2= \\
02: 00\end{array}$ & 0,0090 \\
\hline
\end{tabular}

$* * * \mathrm{p}<0,01, * * \mathrm{p}<0,05, * \mathrm{p}<0,1$. Erros padrão em parêntese.

rif_at_L1 - Receita de Intermediação financeira dividida pelo Ativo total em t-1.

var_ll_L1 - Variação do Lucro Líquido em t-1.

roe_L1 - Lucro líquido dividido pelo patrimônio líquido em t-1.

roa L1 - Lucro operacional dividido pelo ativo total em t-1.

part_merc_L1 - Gau de participação no mercado: Resultado Operacional do banco i dividido pelo Resultado Operacional do banco líder de mercado, em t-1.

tip_bco - Dummy para bancos múltiplos e comerciais.

converg - Dummy para o período de convergência às normas internacionais de contabilidade.

estat - Dummy para bancos de controle estatal (governo federal, estadual ou municipal).

crise - Dummy para indicar o período da crise subprime (Julho de 2007 a abril de 2009).

M1[i] - Intercepto aleatório

Fonte: Elaborada segundo resultados da pesquisa

Esse resultado implica em uma heterogeneidade entre as alternativas, indicando o modelo logit multinomial com efeito aleatório correspondente como o modelo mais apropriado aos dados da pesquisa.

No mesmo sentido, os testes adicionais de comparação entre os modelos indicam que aquele com efeito aleatório parece ser mais ajustado aos dados da pesquisa. Isso pode ser 
comprovado nos resultados do teste de LR - likelihood ratio - e pelo critério de informação de AIC. O teste de LR evidencia um p-valor inferior a 0,05 , ao implicar que o modelo com restrição é mais adequado, e do critério de informação AIC estimado para o modelo com efeito aleatório, dado ao valor estimado ser menor do que o valor estimado para o modelo tradicional.

Para as instituições bancárias com indícios de fraudes, verifica-se na Tabela 1 que as variáveis retorno sobre o patrimônio líquido em t-1 e convergência às normas internacionais de contabilidade foram estatisticamente significantes. Segundo os resultados, o aumento de um ponto percentual do retorno sobre o patrimônio líquido em t-1 eleva a probabilidade de ocorrência de indícios de fraudes em $690,69 \%$, estando as demais variáveis constantes. A convergência às normas internacionais de contabilidade propiciou uma redução na probabilidade de indícios de fraudes em $89,32 \%$, com as demais variáveis constantes.

Destaca-se que, o retorno sobre o patrimônio liquido, embora muito utilizado na literatura sobre desempenho em instituições bancárias, conforme já evidenciado na composição da hipótese de pesquisa, pode apresentar uma perda de poder de comparabilidade, uma vez que é afetado pelo grau de alavancagem da empresa (PRIMO et al, 2013). O que pode ter influenciado no sinal do coeficiente encontrado para instituições bancárias com indícios de fraudes.

Quanto à probabilidade de ocorrência de fraudes, observa-se que as variáveis retorno sobre o ativo em $\mathrm{t}-1$, convergência às normas internacionais de contabilidade e crise financeira foram significantes estatisticamente para empresas condenadas em processos administrativos punitivos. Já as variáveis de controle, convergência às normas internacionais de contabilidade e crise subprime, evidenciam uma relação inversa à probabilidade de ocorrência de fraudes corporativas. Desta forma, a convergência às normas e a crise do subprime influenciam negativamente a probabilidade de ocorrência de fraudes corporativas em 76,67\% e 76,38\%, respectivamente, mantendo-se as demais variáveis constantes.

Para o retorno sobre os ativos verifica-se que sua relação é inversa à probabilidade de ocorrência de fraudes corporativas. Isso implica dizer que o aumento percentual do retorno sobre o ativo em t-1 diminui a probabilidade de fraudes corporativas em quase $100 \%$ $(99,9999 \%)$. Desta forma, verifica-se que um desempenho negativo no período anterior implica em um aumento na probabilidade de ocorrência de fraudes corporativas. Esses achados corroboram a pesquisa de Alexander e Cohen (1996), os quais evidenciaram que os desempenhos anteriores das empresas afetam a ocorrência de crimes corporativos, e refletem a argumentação de Macey (1991), de que o desempenho abaixo do ideal poderá levar os gestores a preferirem um maior nível de risco para elevarem o desempenho da empresa.

Assim, a pressão por desempenhos melhores, visto que o anterior foi abaixo do esperado, pode pressionar os gestores a manipularem os resultados da empresa, a fim de evidenciar um melhor desempenho da instituição bancária.

Diante do exposto, os resultados obtidos para a variável retorno sobre os ativos em t-1, indicam que a hipótese $\mathrm{n}^{\mathrm{o}} 01$ desta pesquisa não pode ser rejeitada. Em outras palavras, o desempenho anterior da instituição bancária influencia negativamente a probabilidade de fraudes corporativas, quando esse desempenho for positivo.

\subsubsection{Dimensão de Pressão: Hipótese n⿳0 02}

A hipótese $\mathrm{n}^{\circ} 02$ da dimensão de pressão supõe uma relação positiva entre a existência de participação nos lucros das instituições bancárias e a probabilidade de ocorrência de fraudes corporativas. Os resultados, encontrados na aplicação dos modelos, estão descritos na Tabela 2. 
Tabela 2 - Relação entre participação nos lucros e fraudes corporativas: Hipótese n⿳0 02

\begin{tabular}{|c|c|c|c|c|c|c|c|c|}
\hline \multirow[b]{4}{*}{ Variáveis } & \multicolumn{4}{|c|}{ Multinomial Logit Tradicional } & \multicolumn{4}{|c|}{ Multinomial Logit com Efeito Aleatório } \\
\hline & \multicolumn{4}{|c|}{ Hipótese $\mathrm{n}^{0} 02$} & \multicolumn{4}{|c|}{ Hipótese $n^{0} 02$} \\
\hline & \multicolumn{2}{|c|}{ Proc. Sem Cond. } & \multicolumn{2}{|c|}{ Proc. Com Cond. } & \multicolumn{2}{|c|}{ Proc. Sem Cond. } & \multicolumn{2}{|c|}{ Proc. Com Cond. } \\
\hline & Coef. & $\begin{array}{l}\text { Odds } \\
\text { Ratio }\end{array}$ & Coef. & $\begin{array}{l}\text { Odds } \\
\text { Ratio }\end{array}$ & Coef. & \begin{tabular}{|l|} 
Odds \\
Ratio
\end{tabular} & Coef. & $\begin{array}{l}\text { Odds } \\
\text { Ratio }\end{array}$ \\
\hline \multirow[t]{2}{*}{ part 11 } & $1,1006^{*}$ & $3,0059^{*}$ & 0,0548 & 1,0563 & 0,8969 & 2,4521 & 0,0989 & 1,1040 \\
\hline & $(0,6532)$ & $(1,9633)$ & $(0,3989)$ & $(0,4214)$ & $(0,7126)$ & $(1,7474)$ & $(0,5381)$ & $(0,5940)$ \\
\hline \multirow[t]{2}{*}{ ln_rem } & 0,2127 & 1,2370 & 0,1638 & 1,1780 & $-0,1737$ & 0,8406 & $-0,5971 * *$ & $0,5504 * *$ \\
\hline & $(0,1544)$ & $(0,1910)$ & $(0,1293)$ & $(0,1523)$ & $(0,2488)$ & $(0,2092)$ & $(0,2936)$ & $(0,1616)$ \\
\hline \multirow[t]{2}{*}{ tip_bco } & 1,2344 & 3,4362 & $-1,2049 * * *$ & $0,2997 * * *$ & 0,8097 & 2,2473 & $-2,1497$ & 0,1165 \\
\hline & $(1,1285)$ & $(3,8777)$ & $(0,4289)$ & $(0,1286)$ & $(1,6344)$ & $(3,6730)$ & $(1,5946)$ & $(0,1858)$ \\
\hline \multirow[t]{2}{*}{ converg } & $-1,9967 *$ & $0,1358 *$ & $-1,8381 * *$ & $0,1591 * *$ & $-1,6137$ & 0,1992 & $-1,5639^{*}$ & $0,2093 *$ \\
\hline & $(1,0390)$ & $(0,1411)$ & $(0,7467)$ & $(0,1188)$ & $(1,0621)$ & $(0,2115)$ & $(0,8001)$ & $(0,1675)$ \\
\hline \multirow[t]{2}{*}{ estat } & 0,6181 & 1,8553 & $1,0152^{* *}$ & $2,7600 * *$ & 0,0458 & 1,0469 & 0,0999 & 1,1051 \\
\hline & $(0,6830)$ & $(1,2671)$ & $(0,4749)$ & $(1,3106)$ & $(0,9995)$ & $(1,0463)$ & $(1,0772)$ & $(1,1904)$ \\
\hline \multirow[t]{2}{*}{ crise } & $-1,8562 *$ & $0,1563^{*}$ & $-1,3027 * *$ & $0,2718^{* *}$ & $-1,6727$ & 0,1877 & $-1,2169^{*}$ & $0,2962 *$ \\
\hline & $(1,0404)$ & $(0,1626)$ & $(0,6225)$ & $(0,1692)$ & $(1,0549)$ & $(0,1981)$ & $(0,6689)$ & $(0,1981)$ \\
\hline \multirow[t]{2}{*}{ M1[i] } & & & & & 1 & 2,7183 & $1,3361 * *$ & $3,8043 * *$ \\
\hline & & & & & 0 & 0,0000 & $(0,5225)$ & $(1,9876)$ \\
\hline \multirow[t]{2}{*}{ Constant } & $-8,7418^{* * *}$ & $0,0002 * * *$ & $-4,8313 * *$ & $0,0080 * *$ & $-3,9019$ & 0,0202 & 5,0638 & 158,1851 \\
\hline & $(2,6939)$ & $(0,0004)$ & $(2,0068)$ & $(0,0160)$ & $(3,7806)$ & $(0,0764)$ & $(4,2548)$ & $(673,054)$ \\
\hline \multicolumn{9}{|l|}{$\operatorname{var}(\mathrm{M} 1[\mathrm{i}])$} \\
\hline \multirow[t]{2}{*}{ Constant } & & & & & 3,3973 & 29,8825 & & \\
\hline & & & & & $(3,0844)$ & $(92,1690)$ & & \\
\hline Obs. & \multicolumn{4}{|c|}{1034} & \multicolumn{4}{|c|}{1034} \\
\hline $\begin{array}{l}\text { Log } \\
\text { likelihood }\end{array}$ & \multicolumn{4}{|c|}{$-227,500$} & \multicolumn{4}{|c|}{$-204,900$} \\
\hline AIC & \multicolumn{4}{|c|}{483,052} & \multicolumn{4}{|c|}{441,884} \\
\hline $\mathrm{BIC}$ & \multicolumn{4}{|c|}{552,229} & \multicolumn{4}{|c|}{520,943} \\
\hline LR test & 45,170 & \multicolumn{7}{|c|}{ Teste de Cramer e Ridder (1991) } \\
\hline $\begin{array}{l}\text { P-valor LR } \\
\text { test }\end{array}$ & 0,0000 & $\begin{array}{c}\mathrm{P}>\mathrm{chi} 2= \\
01: 02\end{array}$ & 0,01 & $\begin{array}{r}\mathrm{P}>\mathrm{cl} \\
01\end{array}$ & & 0000 & $\begin{array}{l}>\operatorname{chi} 2= \\
02: 00\end{array}$ & 0,0240 \\
\hline
\end{tabular}

*** $\mathrm{p}<0,01, * * \mathrm{p}<0,05, * \mathrm{p}<0,1$. Erros padrão em parêntese.

part_ll - Dummy para indicar se os diretores recebem participação nos lucros da empresa.

ln_rem - Logaritmo natural do valor da remuneração trimestral.

tip_bco - Dummy para bancos múltiplos e comerciais.

converg - Dummy para o período de convergência às normas internacionais de contabilidade.

estat - Dummy para bancos de controle estatal (governo federal, estadual ou municipal).

crise - Dummy para indicar o período da crise subprime (Julho de 2007 a abril de 2009).

M1[i] - Intercepto aleatório

Fonte: Elaborada segundo resultados da pesquisa

De acordo com o teste de Cramer e Ridder (1991), a hipótese nula de que as alternativas podem ser agrupadas não foi aceita, dado aos p-valores inferiores a $1 \%$. Os testes adicionais para comparação entre os modelos logit multinomial tradicional e com efeito aleatório, corroboram os resultados do teste de Cramer e Ridder (1991), pois o teste de LR indicou que o modelo com efeito aleatório é mais adequado, ao nível de significância de $1 \%$ e os critérios de informação AIC e BIC demonstram que o modelo com efeito aleatório é o mais ajustado aos dados da pesquisa. Desta forma, evidencia-se a análise dos resultados para o modelo logit multinomial com efeito aleatório.

A hipótese $n^{0} 02$, de que a probabilidade da ocorrência de fraudes corporativas é influenciada positivamente pela participação nos lucros das instituições bancárias brasileiras, foi elaborada em função de um contraponto encontrado entre a literatura da teoria da agência e a economia do crime.

Esta última, representada pelo estudo de Macey (1991), prescreve que os gestores irão buscar aumentar o seu nível de rendimentos, quer pela competência, quer se envolvendo em meios fraudulentos para garanti-los. 
Já a teoria da agência enquadra as políticas de remuneração como custos de monitoramento na atuação dos agentes e, como a participação na lucratividade é classificada como uma política de remuneração, espera-se que a sua relação com a probabilidade de ocorrência de fraudes corporativas seja inversa, reduzindo essa probabilidade.

Pelos resultados discriminados na Tabela 2, a variável participação na lucratividade da instituição bancária não foi estatisticamente significante, seja para a probabilidade de indícios de fraudes ou para a probabilidade de ocorrência de fraudes corporativas. Logo, a hipótese $\mathrm{n}^{\mathrm{o}}$ 02 desta pesquisa, não foi aceita.

No entanto, cabe ressaltar que a variável para a remuneração fixa trimestral evidenciou significância estatística para a probabilidade de ocorrência de fraudes corporativas. Os resultados indicam que quanto maior remuneração fixa percebida pelo gestor, menor é a probabilidade de fraudes corporativas. Uma unidade de variação na remuneração fixa trimestral resulta em um decréscimo da probabilidade de ocorrência de fraudes corporativas em $44,96 \%$, ao se manter as demais variáveis constantes.

Este resultado está de acordo com a literatura de teoria da agência, na qual as políticas de remunerações são consideradas como custos de monitoramento das ações dos agentes, pois auxiliam no alinhamento entre os interesses de agentes e principais (JENSEN; MURPHY, 1990; BYRD; PARRINO; PRITSCH, 1998).

\subsection{Resultados das Hipóteses da Dimensão de Oportunidade do Triângulo de Fraude}

As oportunidades resultam de circunstâncias que oferecem chances para o gestor cometer fraudes, estando diretamente interligadas aos problemas não compartilháveis do indivíduo, que na intenção de corrigi-los secretamente podem se utilizar de meios fraudulentos.

Para mensurar a dimensão de oportunidade do triângulo de fraude de Cressey (1953) foram propostas duas hipóteses individuais. Esta seção destina-se a apresentação dos resultados da mensuração dos modelos criados para testar as hipóteses individuais da dimensão de oportunidade.

\subsubsection{Dimensão de Oportunidade: Hipótese $n^{0} 03$}

A hipótese de $\mathrm{n}^{\circ} 03$ testa a relação entre a probabilidade de fraudes corporativas e baixos indicadores de governança corporativa. Na Tabela 3, os resultados do teste de Cramer e Ridder (1991) indicam que, exceto para as alternativas 02 e 00, os agrupamentos entre as alternativas não podem ser realizados ao nível de significância de $1 \%$. Esse resultado implica uma heterogeneidade entre as alternativas, possibilitando a conclusão de que o modelo logit multinomial com efeito aleatório corresponde ao modelo mais apropriado aos dados da pesquisa. Esse resultado foi corroborado pelos testes adicionais de comparação, LR - likelihood ratio - e pelo critério de informação de AIC.

Analisando os dados da Tabela 3, a variável tamanho da diretoria foi estatisticamente significante para a probabilidade de indícios de fraudes corporativas. Destarte, o aumento de um diretor implica em um acréscimo na probabilidade de indícios de fraudes corporativas em $577,71 \%$, com as demais variáveis constantes.

Essa variável pode ser considerada como uma medida de poder da diretoria sobre o conselho de administração, dado que o aumento do número de diretores implica em aumento dos custos de monitoramento e problemas de coordenação.

Nesse sentido, Dechow, Sloan e Sweeney (1996) encontraram em sua pesquisa que a ineficiência do acompanhamento da gestão, representada por uma estrutura fraca de governança corporativa, impulsiona a manipulação de resultados e, consequentemente a fraudes 
corporativas.

Para as instituições que cometeram fraudes corporativas, as variáveis que apresentam significância estatística são: empresas de auditoria big five e o selo de governança corporativa da BM\&F Bovespa.

Tabela 3 - Relação entre governança corporativa e fraudes corporativas: Hipótese no 04

\begin{tabular}{|c|c|c|c|c|c|c|c|c|}
\hline \multirow[b]{4}{*}{ Variáveis } & \multicolumn{4}{|c|}{ Multinomial Logit Tradicional } & \multirow{2}{*}{\multicolumn{4}{|c|}{$\begin{array}{c}\text { Multinomial Logit com Intercepto Aleatório } \\
\text { Hipótese } n^{0} 03\end{array}$}} \\
\hline & \multicolumn{4}{|c|}{ Hipótese $n^{0} 03$} & & & & \\
\hline & \multicolumn{2}{|c|}{ Proc. Sem Cond. } & \multicolumn{2}{|c|}{ Proc. Com Cond. } & \multicolumn{2}{|c|}{ Proc. Sem Cond. } & \multicolumn{2}{|c|}{ Proc. Com Cond. } \\
\hline & Coef. & $\begin{array}{l}\text { Odds } \\
\text { Ratio } \\
\end{array}$ & Coef. & \begin{tabular}{|l|} 
Odds \\
Ratio \\
\end{tabular} & Coef. & $\begin{array}{l}\text { Odds } \\
\text { Ratio }\end{array}$ & Coef. & $\begin{array}{l}\text { Odds } \\
\text { Ratio }\end{array}$ \\
\hline \multirow[t]{2}{*}{ mci2 } & 0,1354 & 1,145 & $-0,0795$ & 0,9236 & 0,1277 & 1,1362 & $-0,1796$ & 0,8356 \\
\hline & $(0,1044)$ & $(0,1195)$ & $(0,1163)$ & $(0,1074)$ & $(0,1118)$ & $(0,1271)$ & $(0,1388)$ & $(0,1160)$ \\
\hline \multirow[t]{2}{*}{ tcf 2} & 0,0115 & 1,0115 & $0,0297 * * *$ & $1,0301 * * *$ & 0,0091 & 1,0091 & 0,0158 & 1,0159 \\
\hline & $(0,0114)$ & $(0,0115)$ & $(0,0112)$ & $(0,0115)$ & $(0,0121)$ & $(0,0122)$ & $(0,0163)$ & $(0,0166)$ \\
\hline \multirow[t]{2}{*}{ tca2 } & $-0,004$ & 0,996 & $-0,0197 *$ & $0,9804 *$ & $-0,0028$ & 0,9972 & $-0,0206$ & 0,9796 \\
\hline & $(0,0063)$ & $(0,0062)$ & $(0,0109)$ & $(0,0107)$ & $(0,0068)$ & $(0,0067)$ & $(0,0209)$ & $(0,0205)$ \\
\hline \multirow[t]{2}{*}{ ceo_rot } & 1,2648 & 3,5425 & $-0,5365$ & 0,5848 & 1,1869 & 3,2769 & $-1,1276$ & 0,3238 \\
\hline & $(0,8096)$ & $(2,8680)$ & $(1,1252)$ & $(0,6580)$ & $(0,8171)$ & $(2,6774)$ & $(1,2080)$ & $(0,3912)$ \\
\hline \multirow[t]{2}{*}{ big five } & $-1,1515$ & 0,3162 & $-1,5314 * * *$ & $0,2162 * * *$ & $-1,4296$ & 0,2394 & $-2,3549 * *$ & $0,0949 * *$ \\
\hline & $(0,8227)$ & $(0,2601)$ & $(0,5554)$ & $(0,1201)$ & $(0,8821)$ & $(0,2112)$ & $(1,0487)$ & $(0,0995)$ \\
\hline \multirow[t]{2}{*}{ selo_gov } & $-1,3131$ & 0,269 & $-2,3024 * * *$ & $0,1000 * * *$ & $-1,3573$ & 0,2574 & $-2,0727 * *$ & $0,1258 * *$ \\
\hline & $(0,8486)$ & $(0,2283)$ & $(0,8734)$ & $(0,0874)$ & $(0,8786)$ & $(0,2261)$ & $(0,9427)$ & $(0,1186)$ \\
\hline \multirow{2}{*}{ ln tam_dir } & $1,5124 * * *$ & $4,5377 * * *$ & $1,4211 * * *$ & $4,1416^{* * * *}$ & $1,5638^{* * *}$ & $4,7771 * * *$ & 0,6773 & 1,9686 \\
\hline & $(0,5189)$ & $(2,3544)$ & $(0,4374)$ & $(1,8115)$ & $(0,5535)$ & $(2,6440)$ & $(1,0483)$ & $(2,0637)$ \\
\hline \multirow[t]{2}{*}{ tip_bco } & $2,5353 *$ & $12,6199^{*}$ & $-0,2978$ & 0,7424 & $2,7250 *$ & $15,2564 *$ & $-1,5878$ & 0,2044 \\
\hline & $(1,4162)$ & $(17,872)$ & $(0,5938)$ & $(0,4409)$ & $(1,5670)$ & $(23,907)$ & $(1,8606)$ & $(0,3803)$ \\
\hline \multirow[t]{2}{*}{ estat } & 1,0285 & 2,7967 & $-0,4591$ & 0,6319 & 1,0807 & 2,9466 & 0,4285 & 1,535 \\
\hline & $(0,9650)$ & $(2,6988)$ & $(0,8706)$ & $(0,5501)$ & $(1,0002)$ & $(2,9472)$ & $(1,4917)$ & $(2,2898)$ \\
\hline \multirow[t]{2}{*}{ crise } & 0,2839 & 1,3283 & $-0,45$ & 0,6376 & 0,2902 & 1,3368 & 0,0594 & 1,0612 \\
\hline & $(0,6723)$ & $(0,8930)$ & $(0,7696)$ & $(0,4907)$ & $(0,6791)$ & $(0,9078)$ & $(0,8456)$ & $(0,8974)$ \\
\hline \multirow[t]{2}{*}{ M1[i] } & & & & & 1 & 2,7183 & 3,9323 & 51,0238 \\
\hline & & & & & 0,0000 & 0,0000 & $(3,2071)$ & $(163,638)$ \\
\hline \multirow[t]{2}{*}{ Constant } & $-9,7174 * * *$ & $0,0001 * * *$ & $-5,1598 * * *$ & $0,0057 * * *$ & $-9,9380 * * *$ & $0,0000 * * *$ & $(3,2242)$ & 0,0398 \\
\hline & $(2,5213)$ & $(0,0002)$ & $(1,4292)$ & $(0,0082)$ & $(2,7164)$ & $(0,0001)$ & $(3,3677)$ & $(0,1340)$ \\
\hline \multicolumn{9}{|l|}{$\operatorname{var}(\mathrm{M} 1[\mathrm{i}])$} \\
\hline \multirow[t]{2}{*}{ Constant } & & & & & & & 0,2727 & 1,3135 \\
\hline & & & & & & & $(0,4462)$ & $(0,5860)$ \\
\hline Obs. & \multicolumn{4}{|c|}{754} & & & & \\
\hline $\begin{array}{l}\text { Log } \\
\text { Likelihood }\end{array}$ & & & 700 & & & & & \\
\hline AIC & & & 356 & & & & & \\
\hline BIC & & & 114 & & & 455 & & \\
\hline LR test & 21 , & & & & e de Cramer & Ridder (19) & & \\
\hline $\begin{array}{l}\text { P-valor LR } \\
\text { test }\end{array}$ & 0,0 & & $\begin{array}{c}\mathrm{P}>\text { chi } 2= \\
01: 02\end{array}$ & 0,0660 & $\begin{array}{c}\mathrm{P}>\mathrm{chi} 2= \\
01: 00\end{array}$ & 0,0000 & $\begin{array}{c}\mathrm{P}>\mathrm{chi} 2= \\
02: 00\end{array}$ & 0,0560 \\
\hline
\end{tabular}

$* * * \mathrm{p}<0,01, * * \mathrm{p}<0,05, * \mathrm{p}<0,1$. Erros padrão em parêntese.

mci2 - Número de membros independentes no conselho de administração elevado ao quadrado.

tcf2 - Número de membros do conselho fiscal elevado ao quadrado.

tca2 - Número de membros do conselho de administração elevado ao quadrado.

ceo_rot - Dummy para mudança de um CEO.

big_five - Dummy para indicar se a empresa de auditoria é uma big five ou não.

selo_gov - Dummy para empresas que estão listadas nos segmentos de governança corporativa da BM\&F Bovespa.

ln_tam_dir - Logaritmo natural do número de diretores da empresa

tip bco - Dummy para bancos múltiplos e comerciais.

estat - Dummy para bancos de controle estatal (governo federal, estadual ou municipal).

crise - Dummy para indicar o período da crise subprime (Julho de 2007 a abril de 2009).

M1[i] - Intercepto aleatório

Fonte: Elaborada segundo resultados da pesquisa 
A variável big five influenciou de forma inversa a fraude corporativa. A contratação de uma firma de auditoria, considerada como big five, diminui a probabilidade de ocorrência de fraudes corporativas, fato que corrobora os achados de Lennox e Pittman (2010), refletindo a importância econômica da qualidade da auditoria. Segundo os achados evidenciados na Tabela 3, empresas big five reduzem as chances de ocorrência de fraudes corporativas em $90,51 \%$, com as demais variáveis constantes.

Ainda, verifica-se que o enquadramento da instituição bancária em um dos selos de governança corporativa da $\mathrm{BM} \& \mathrm{~F}$ Bovespa influencia negativamente a probabilidade de ocorrência de fraudes corporativas. Portanto, instituições bancárias com um selo de governança corporativa diminuem as chances de ocorrência de fraudes corporativas em $87,42 \%$, mantendo as demais variáveis constantes.

O aumento no número de diretores implica no aumento de conflito de agência, dado que pela diferença de objetivos entre proprietários e gestores, existe uma boa razão para acreditar que o agente não atuará sempre no melhor interesse do principal, gerando custos com problemas de agência (JENSEN; MECKLING, 1976).

A contratação de empresas de auditoria com maior reputação no mercado, conhecidas como big five auxiliará no controle das ações dos gestores, bem como o enquadramento da instituição bancária em um dos selos de governança corporativa da BM\&F da Bovespa.

Portanto, o aumento do número de diretores, a contratação de empresas de auditoria não consideradas como big five, e o não enquadramento da instituição nos selos de governança corporativa, podem ser considerados como um baixo indicador de governança corporativa. Logo, não se pode rejeitar a hipótese de que a probabilidade de ocorrência de fraudes corporativas é influenciada positivamente por baixos indicadores de governança corporativa.

\subsubsection{Dimensão de Oportunidade: Hipótese $n^{\circ} 04$}

A Tabela 4 traz o resultado do teste aplicado para a hipótese $n^{\circ} 04$, elaborada para verificar se há relação entre a probabilidade de ocorrência de fraudes corporativas e o tamanho da empresa.

Conforme os resultados do teste de Cramer e Ridder (1991), evidenciados na Tabela 4, percebe-se que a hipótese nula de que as alternativas podem ser agrupadas não foi aceita, dados os p-valores inferiores a 5\%. Nesse mesmo sentido, os testes de comparação adicional, teste LR e critérios de informação AIC e BIC, indicam que o modelo logit multinomial com efeito aleatório parece ser o mais ajustado aos dados da pesquisa. Portanto, evidencia-se a análise dos resultados para o modelo logit multinomial com efeito aleatório.

Os resultados evidenciados na Tabela 4 indicam que o tamanho da instituição bancária e a convergência às normas internacionais de contabilidade influenciam significativamente na probabilidade de indícios de fraudes. $\mathrm{O}$ aumento da instituição acresce essa probabilidade em $30,10 \%$, enquanto a convergências às normas internacionais produz um decréscimo na probabilidade de indícios de fraude de $90,85 \%$. Já a probabilidade de ocorrência de fraudes corporativas é influenciada negativamente pelas variáveis de controle: convergências às normas internacionais de contabilidade e crise subprime, diminuindo as chances de ocorrência de fraudes em $81,96 \%$ e $79,15 \%$, respectivamente.

Diante dos resultados evidenciados na Tabela 4 , não se pode confirmar a hipótese $\mathrm{n}^{\circ} 04$, de que a probabilidade de ocorrência de fraudes corporativas é influenciada positivamente pelo tamanho da instituição bancária. Este resultado não se alinha com os achados de Lennox e Pittman (2010), que utilizaram a variável para controlar o efeito do tamanho em fraudes corporativas. 
Tabela 4 - Relação entre tamanho e fraudes corporativas: Hipótese n⿳0 04

\begin{tabular}{|c|c|c|c|c|c|c|c|c|}
\hline \multirow[b]{4}{*}{ Variáveis } & \multicolumn{4}{|c|}{ Multinomial Logit Tradicional } & \multicolumn{4}{|c|}{ Multinomial Logit com Efeito Aleatório } \\
\hline & \multicolumn{4}{|c|}{ Hipótese n 04} & \multicolumn{4}{|c|}{ Hipótese nº4 } \\
\hline & \multicolumn{2}{|c|}{ Proc. Sem Cond. } & \multicolumn{2}{|c|}{ Proc. Com Cond. } & \multicolumn{2}{|c|}{ Proc. Sem Cond. } & \multicolumn{2}{|c|}{ Proc. Com Cond. } \\
\hline & Coef. & $\begin{array}{l}\text { Odds } \\
\text { Ratio }\end{array}$ & Coef. & $\begin{array}{l}\text { Odds } \\
\text { Ratio }\end{array}$ & Coef. & $\begin{array}{l}\text { Odds } \\
\text { Ratio }\end{array}$ & Coef. & $\begin{array}{l}\text { Odds } \\
\text { Ratio }\end{array}$ \\
\hline \multirow[t]{2}{*}{$\ln$ ativo to } & $0,2891 * * *$ & $1,3352 * * *$ & $0,3617 * * *$ & $1,4358 * * *$ & $0,2631 * *$ & $1,3010^{* *}$ & 0,1492 & 1,1610 \\
\hline & $(0,0893)$ & $(0,1192)$ & $(0,0801)$ & $(0,1150)$ & $(0,1079)$ & $(0,1403)$ & $(0,1774)$ & $(0,2060)$ \\
\hline \multirow[t]{2}{*}{ tip_bco } & 0,5734 & 1,7743 & $-1,1857 * * *$ & $0,3055 * * *$ & 0,6077 & 1,8361 & $-1,5263$ & 0,2173 \\
\hline & $(0,8285)$ & $(1,4701)$ & $(0,4376)$ & $(0,1337)$ & $(0,9759)$ & $(1,7919)$ & $(1,1891)$ & $(0,2584)$ \\
\hline \multirow[t]{2}{*}{ converg } & $-2,3665 * *$ & $0,0938^{* *}$ & $-1,6636^{* * *}$ & $0,1895 * * *$ & $-2,3918 * *$ & $0,0915^{* *}$ & $-1,7128 * * *$ & $0,1804 * * *$ \\
\hline & $(1,0232)$ & $(0,0960)$ & $(0,6252)$ & $(0,1185)$ & $(1,0253)$ & $(0,0938)$ & $(0,6542)$ & $(0,1180)$ \\
\hline \multirow[t]{2}{*}{ estat } & 0,0233 & 1,0236 & $0,9742 * *$ & $2,6491 * *$ & $-0,1141$ & 0,8922 & 0,7095 & 2,0329 \\
\hline & $(0,4483)$ & $(0,4589)$ & $(0,4012)$ & $(1,0628)$ & $(0,5344)$ & $(0,4768)$ & $(0,7947)$ & $(1,6157)$ \\
\hline \multirow[t]{2}{*}{ crise } & $-0,6339$ & 0,5305 & $-1,5062 * *$ & $0,2218 * *$ & $-0,6604$ & 0,5166 & $-1,5677 * *$ & $0,2085 * *$ \\
\hline & $(0,4899)$ & $(0,2599)$ & $(0,6169)$ & $(0,1368)$ & $(0,4937)$ & $(0,2551)$ & $(0,6401)$ & $(0,1335)$ \\
\hline \multirow[t]{2}{*}{ M1[i] } & & & & & 1 & 2,7183 & 2,2496 *** & $9,4841 * * *$ \\
\hline & & & & & 0 & 0,0000 & $(0,8626)$ & $(8,1815)$ \\
\hline \multirow[t]{2}{*}{ Constant } & $-8,8474 * * *$ & $0,0001 * * *$ & $-8,7350 * * *$ & $0,0002 * * *$ & $-8,6366^{* * *}$ & $0,0002 * * *$ & $-5,8552 *$ & $0,0029 *$ \\
\hline & $(1,8434)$ & $(0,0003)$ & $(1,5625)$ & $(0,0003)$ & $(2,2292)$ & $(0,0004)$ & $(3,2689)$ & $(0,0094)$ \\
\hline \multicolumn{9}{|l|}{$\operatorname{var}(\mathrm{M} 1[\mathrm{i}])$} \\
\hline \multirow[t]{2}{*}{ Constant } & & & & & 0,4934 & 1,6379 & & \\
\hline & & & & & $(0,3702)$ & $(0,6064)$ & & \\
\hline Obs. & \multicolumn{4}{|c|}{1900} & \multicolumn{4}{|c|}{1900} \\
\hline $\begin{array}{l}\text { Log } \\
\text { likelihood }\end{array}$ & \multicolumn{4}{|c|}{$-359,000$} & \multicolumn{4}{|c|}{$-341,400$} \\
\hline AIC & \multicolumn{4}{|c|}{741,993} & \multicolumn{4}{|c|}{710,873} \\
\hline $\mathrm{BIC}$ & \multicolumn{4}{|c|}{808,589} & \multicolumn{4}{|c|}{788,568} \\
\hline LR test & \multicolumn{2}{|c|}{35,120} & \multicolumn{6}{|c|}{ Teste de Cramer e Ridder (1991) } \\
\hline $\begin{array}{l}\text { P-valor LR } \\
\text { test }\end{array}$ & 0,00 & & $\begin{array}{c}\mathrm{P}>\mathrm{chi} 2= \\
01: 02\end{array}$ & 0,0020 & $\begin{array}{c}\mathrm{P}>\operatorname{chi} 2= \\
01: 00\end{array}$ & 0,0000 & $\begin{array}{c}\mathrm{P}>\operatorname{chi} 2= \\
02: 00\end{array}$ & 0,0010 \\
\hline
\end{tabular}

$* * * \mathrm{p}<0,01,{ }^{* *} \mathrm{p}<0,05,{ }^{*} \mathrm{p}<0,1$. Erros padrão em parêntese.

In_ativo_total - Log natural do ativo total.

tip_bco - Dummy para bancos múltiplos e comerciais.

converg - Dummy para o período de convergência às normas internacionais de contabilidade.

estat - Dummy para bancos de controle estatal (governo federal, estadual ou municipal).

crise - Dummy para indicar o período da crise subprime (Julho de 2007 a abril de 2009).

M1[i] - Intercepto aleatório

Fonte: Elaborada segundo resultados da pesquisa

Esperava-se que essa variável indicasse um comportamento positivo e significante em relação a ocorrência de fraudes corporativas, dado que uma maior complexidade das corporações, em função do tamanho, tende a facilitar a perpetração de fraudes na gestão, pois como afirmam Ryan e Wiggins (2001), quando uma empresa fica maior os gestores têm mais recursos à sua disposição e os conflitos de agência aumentam. No entanto, para a amostra da pesquisa, essa argumentação não foi corroborada já que a significância estatística para a variável tamanho não foi obtida para a probabilidade de ocorrência de fraudes corporativas.

\subsection{Resultados das Hipóteses da Dimensão de Racionalização do Triângulo de Fraude}

A tese por traz da dimensão de racionalização é a de que o fraudador analisa o ato de cometer o ilícito como se ele fosse correto, portanto, é uma autojustificação de que o ato de cometer uma fraude é justificável e aceitável. A racionalização, então, é um processo cognitivo, e para sua mensuração são propostas hipóteses que trazem características demográficas dos gestores, como a idade, nível educacional, formação na área de negócios, predominância do gênero feminino. Além dessas características, busca-se contemplar aspectos ligados a ações de punição para atos fraudulentos, sobretudo em função da dificuldade de obtenção de dados 
psicométricos convencionais de altos executivos (HAMBRICK, 2007).

Esta seção destina-se a apresentar os resultados dos testes das hipóteses elaboradas segundo a dimensão de racionalização do triângulo de Cressey (1993).

\subsubsection{Dimensão de Racionalização: Hipótese n ${ }^{\circ} 05$}

A Tabela 5 evidencia os resultados obtidos na mensuração da hipótese $n^{\circ} 05$, que trata do relacionamento entre a idade do CEO e a probabilidade de ocorrência de fraudes corporativas.

Tabela 5 - Relação entre idade do CEO e fraudes corporativas: Hipótese $\mathbf{n}^{0} 05$

\begin{tabular}{|c|c|c|c|c|c|c|c|c|}
\hline \multirow[b]{4}{*}{ Variáveis } & \multicolumn{4}{|c|}{ Multinomial Logit Tradicional } & \multicolumn{4}{|c|}{ Multinomial Logit com Efeito Aleatório } \\
\hline & \multicolumn{4}{|c|}{ Hipótese no 05} & \multicolumn{4}{|c|}{ Hipótese no 05} \\
\hline & \multicolumn{2}{|c|}{ Proc. Sem Cond. } & \multicolumn{2}{|c|}{ Proc. Com Cond. } & \multicolumn{2}{|c|}{ Proc. Sem Cond. } & \multicolumn{2}{|c|}{ Proc. Com Cond. } \\
\hline & Coef. & $\begin{array}{l}\text { Odds } \\
\text { Ratio }\end{array}$ & Coef. & $\begin{array}{l}\text { Odds } \\
\text { Ratio }\end{array}$ & Coef. & $\begin{array}{l}\text { Odds } \\
\text { Ratio }\end{array}$ & Coef. & $\begin{array}{l}\text { Odds } \\
\text { Ratio }\end{array}$ \\
\hline \multirow[t]{2}{*}{ idade } & 0,0418 & 1,0427 & 0,0184 & 1,0186 & 0,0473 & 1,0484 & 0,0458 & 1,0468 \\
\hline & $(0,0292)$ & $(0,0304)$ & $(0,0212)$ & $(0,0216)$ & $(0,0383)$ & $(0,0401)$ & $(0,0404)$ & $(0,0423)$ \\
\hline \multirow{2}{*}{ In_ativo_to } & $0,5365 * * *$ & $1,7100 * * *$ & 0,0855 & 1,0893 & 0,3198 & 1,3769 & $-0,3405$ & 0,7114 \\
\hline & $(0,1675)$ & $(0,2863)$ & $(0,0946)$ & $(0,1030)$ & $(0,2508)$ & $(0,3453)$ & $(0,3455)$ & $(0,2458)$ \\
\hline \multirow{2}{*}{ tip_bco } & 0,7380 & 2,0918 & $-1,4718^{* *}$ & $0,2295 * *$ & $-0,4750$ & 0,6219 & $-4,5003$ & 0,0111 \\
\hline & $(1,1780)$ & $(2,4642)$ & $(0,6215)$ & $(0,1426)$ & $(1,9205)$ & $(1,1944)$ & $(2,7395)$ & $(0,0304)$ \\
\hline \multirow[t]{2}{*}{ estat } & 1,1266 & 3,0851 & 0,6665 & 1,9475 & 0,3520 & 1,4219 & $-0,3203$ & 0,7259 \\
\hline & $(0,7726)$ & $(2,3835)$ & $(0,5304)$ & $(1,0329)$ & $(1,0982)$ & $(1,5616)$ & $(1,3571)$ & $(0,9852)$ \\
\hline \multirow[t]{2}{*}{ crise } & $-1,0793$ & 0,3398 & $-0,4897$ & 0,6128 & $-1,0918$ & 0,3356 & $-0,4911$ & 0,6120 \\
\hline & $(1,0498)$ & $(0,3568)$ & $(0,6337)$ & $(0,3883)$ & $(1,0556)$ & $(0,3543)$ & $(0,6675)$ & $(0,4085)$ \\
\hline \multirow[t]{2}{*}{ M1[i] } & & & & & 1 & 2,7183 & $2,0162 *$ & $7,5097 *$ \\
\hline & & & & & 0 & 0,0000 & $(1,1626)$ & $(8,7310)$ \\
\hline \multirow[t]{2}{*}{ Constant } & $-16,4795 * * *$ & $0,0000 * * *$ & $-4,6938 * *$ & $0,0092 * *$ & $-12,3069 * *$ & $0,0000 * *$ & 2,2285 & 9,2862 \\
\hline & $(4,0484)$ & 0,0000 & $(2,3178)$ & $(0,0212)$ & $(5,3871)$ & 0,0000 & $(6,6740)$ & $(61,9760)$ \\
\hline \multicolumn{9}{|l|}{$\operatorname{var}(\mathrm{M} 1[\mathrm{i}])$} \\
\hline \multirow[t]{2}{*}{ Constant } & & & & & 1,0045 & 2,7305 & & \\
\hline & & & & & $(1,3477)$ & $(3,6799)$ & & \\
\hline Obs. & \multicolumn{4}{|c|}{766} & \multicolumn{4}{|c|}{766} \\
\hline $\begin{array}{l}\text { Log } \\
\text { likelihood }\end{array}$ & \multicolumn{4}{|c|}{$-171,000$} & \multicolumn{4}{|c|}{$-161,600$} \\
\hline AIC & \multicolumn{4}{|c|}{366,071} & \multicolumn{4}{|c|}{351,116} \\
\hline BIC & \multicolumn{4}{|c|}{421,765} & \multicolumn{4}{|c|}{416,092} \\
\hline LR test & \multicolumn{2}{|c|}{18,960} & \multicolumn{6}{|c|}{ Teste de Cramer e Ridder (1991) } \\
\hline $\begin{array}{l}\text { P-valor LR } \\
\text { test }\end{array}$ & 0,00 & & $\begin{array}{c}\mathrm{P}>\mathrm{chi} 2= \\
01: 02\end{array}$ & 0,0050 & $\begin{array}{c}\mathrm{P}>\mathrm{chi} 2= \\
01: 00\end{array}$ & 0,0010 & $\begin{array}{c}\mathrm{P}>\mathrm{chi} 2= \\
02: 00\end{array}$ & 0,0990 \\
\hline
\end{tabular}

$* * * p<0,01, * * p<0,05, * p<0,1$. Erros padrão em parêntese.

idade - Idade do CEO.

In ativo total - Log natural do ativo total.

tip_bco - Dummy para bancos múltiplos e comerciais.

estat - Dummy para bancos de controle estatal (governo federal, estadual ou municipal).

crise - Dummy para indicar o período da crise subprime (Julho de 2007 a abril de 2009).

M1[i] - Intercepto aleatório

Fonte: Elaborada segundo resultados da pesquisa

Examina-se na Tabela 5 que os resultados do teste de Cramer e Ridder (1991) assinalam que, exceto para as alternativas 02 e 00 , os agrupamentos entre as alternativas não podem ser realizados ao nível de significância de 5\%. Logo, o modelo logit multinomial com efeito aleatório corresponde ao modelo mais apropriado aos dados da pesquisa. Consubstanciando os achados do teste de Cramer e Ridder (1991), os testes adicionais de comparação - LR likelihood ratio - e pelo critério de informação de AIC - também indicam que o modelo logit com efeito aleatório possui um melhor ajuste aos dados. 
Segundo as informações da Tabela 5, a idade do gestor não apresenta influência significante na probabilidade de indícios de fraudes e na ocorrência de fraudes corporativas. Isso implica em dizer que a idade do CEO não parece ser um fator relevante para a mensuração da probabilidade de fraudes corporativas, em instituições bancárias brasileiras. Esse resultado não corrobora os estudos de Troy, Smith e Domino (2011), Kelley, Ferrel e Skinner (1990), Zahra, Priem e Rasheed (2007).

Para estes autores, a idade está diretamente relacionada com o desenvolvimento moral, cuidado na tomada de decisão, diagnóstico preciso das informações e maior disponibilidade em reconsiderar. Além de o aumento da idade proporcionar um conjunto mais amplo de experiências vivenciadas e maturidade, o que, segundo Troy, Smith e Domino (2011), reflete nas repercussões da descoberta de fraudes nas demonstrações financeiras, e nos custos reputacionais individuais daqueles que cometerem essas violações.

Destaque-se que o sinal esperado para a variável não foi confirmado, tendo em vista que tanto para a probabilidade de indícios quanto para a de ocorrência de fraudes corporativas o sinal foi positivo, ao indicar que quanto maior a idade, maior a probabilidade de ocorrência de fraudes. Portanto, não se pode aceitar a hipótese $\mathrm{n}^{\mathrm{o}} 05$ de que a probabilidade de ocorrência de fraudes corporativas é influenciada negativamente pela idade dos gestores.

\subsubsection{Dimensão de Racionalização: Hipótese $n^{\circ} 06$}

A hipótese $\mathrm{n}^{\mathrm{o}} 06$ testa a relação entre a predominância do gênero feminino na administração da instituição bancária - conselho de administração, conselho fiscal e diretoria executiva - e a probabilidade de ocorrência de fraudes corporativas.

Examina-se na Tabela 6 que os resultados do teste de Cramer e Ridder (1991) indicam que os agrupamentos entre as alternativas não podem ser realizados ao nível de significância de 5\%. Esse resultado foi confirmado pelos testes de comparação adicional em que o teste de LR demonstra um p-valor inferior a 0,05 , implicando que o modelo com restrição é mais adequado. Os valores dos critérios de informação AIC e BIC, por possuírem valores inferiores aos estimados para o modelo logit tradicional, também permitem inferir que o modelo logit com efeito aleatório parece ser mais ajustado aos dados da pesquisa.

Conforme se observa na Tabela 6 as variáveis utilizadas para analisar a predominância do gênero feminino na administração, não evidenciaram significância estatística para a probabilidade de indícios de fraudes. Enquanto para a probabilidade de ocorrência de fraudes corporativas, a predominância do gênero feminino foi negativamente significante. Dessa forma, um aumento nessa variável reduz a probabilidade de fraudes corporativas em 99,50\%.

Os resultados obtidos para a predominância do gênero na diretoria executiva assemelham-se com as pesquisas de Steffensmeier, Schwartz e Roche (2013) e com as afirmações de Reynolds (2006), Zahra, Priem e Rasheed (2007) e Kelley, Ferrel e Skinner (1990) sobre o comportamento do gênero quanto a fraudes. Segundo esses autores, as gestoras são menos suscetíveis de cometerem atos fraudulentos que os gestores.

Portanto, a hipótese $\mathrm{n}^{\mathrm{o}} 06$ desta pesquisa, de que a probabilidade de ocorrência de fraudes corporativas é influenciada negativamente pela predominância do gênero feminino na administração da instituição bancária, não pode ser rejeitada. 
Tabela 6 - Relação entre predominância do gênero feminino e fraudes corporativas: Hipótese $n^{0} 6$

\begin{tabular}{|c|c|c|c|c|c|c|c|c|}
\hline \multirow[b]{4}{*}{ Variáveis } & \multicolumn{4}{|c|}{ Multinomial Logit Tradicional } & \multicolumn{4}{|c|}{ Multinomial Logit com Efeito Aleatório } \\
\hline & \multicolumn{4}{|c|}{ Hipótese $n^{0} 6$} & \multicolumn{4}{|c|}{ Hipótese $n^{0} 6$} \\
\hline & \multicolumn{2}{|c|}{ Proc. Sem Cond. } & \multicolumn{2}{|c|}{ Proc. Com Cond. } & \multicolumn{2}{|c|}{ Proc. Sem Cond. } & \multicolumn{2}{|c|}{ Proc. Com Cond. } \\
\hline & Coef. & \begin{tabular}{|l|} 
Odds \\
Ratio \\
\end{tabular} & Coef. & $\begin{array}{l}\text { Odds } \\
\text { Ratio } \\
\end{array}$ & Coef. & \begin{tabular}{|l|} 
Odds \\
Ratio \\
\end{tabular} & Coef. & $\begin{array}{l}\text { Odds } \\
\text { Ratio } \\
\end{array}$ \\
\hline \multirow[t]{2}{*}{ pren_mul_cf } & 2,9458 & 19,0258 & $-3,5587 *$ & $0,0285^{*}$ & 2,5368 & 12,6392 & $-3,3287$ & 0,0358 \\
\hline & $(2,1046)$ & $(40,0419)$ & $(2,0029)$ & $(0,0570)$ & $(2,2510)$ & $(28,4510)$ & $(2,1918)$ & $(0,0786)$ \\
\hline \multirow[t]{2}{*}{ pren_mul_ca } & 0,4775 & 1,612 & $-2,1227$ & 0,1197 & $-0,5500$ & 0,5770 & $-2,2158$ & 0,1091 \\
\hline & $(2,6723)$ & $(4,3077)$ & $(2,2581)$ & $(0,2703)$ & $(2,9579)$ & $(1,7067)$ & $(2,6811)$ & $(0,2924)$ \\
\hline \multirow[t]{2}{*}{ pren_mul_dir } & $-1,4114$ & 0,2438 & $-5,1305$ & 0,0059 & $-2,7865$ & 0,0616 & $-7,5829 * *$ & $0,0005 * *$ \\
\hline & $(2,8894)$ & $(0,7044)$ & $(3,1857)$ & $(0,0188)$ & $(3,4631)$ & $(0,2134)$ & $(3,7290)$ & $(0,0019)$ \\
\hline \multirow[t]{2}{*}{$\ln$ ativo to } & $0,4972 * * *$ & $1,6441 * * *$ & $0,3426^{* * *}$ & $1,4086^{* * * *}$ & $0,3661 *$ & $1,4421 *$ & $-0,019$ & 0,9812 \\
\hline & $(0,1300)$ & $(0,2138)$ & $(0,0920)$ & $(0,1296)$ & $(0,1882)$ & $(0,2714)$ & $(0,2771)$ & $(0,2719)$ \\
\hline \multirow[t]{2}{*}{ tip_bco } & 1,4195 & 4,1351 & $-1,0034 * *$ & $0,3666 * *$ & 1,4110 & 4,1002 & $-1,7239$ & 0,1784 \\
\hline & $(0,9313)$ & $(3,8512)$ & $(0,4646)$ & $(0,1703)$ & $(1,2318)$ & $(5,0507)$ & $(1,4385)$ & $(0,2566)$ \\
\hline \multirow[t]{2}{*}{ estat } & 0,0731 & 1,0758 & $1,2020 * * *$ & $3,3269 * * *$ & 0,0200 & 1,0202 & 1,0410 & 2,8321 \\
\hline & $(0,5704)$ & $(0,6136)$ & $(0,4557)$ & $(1,5159)$ & $(0,7472)$ & $(0,7622)$ & $(0,9767)$ & $(2,7660)$ \\
\hline \multirow[t]{2}{*}{ crise } & $-0,2317$ & 0,7932 & $-1,2202$ & 0,2952 & $-0,1886$ & 0,8282 & $-1,1729$ & 0,3095 \\
\hline & $(0,6310)$ & $(0,5005)$ & $(0,7449)$ & $(0,2199)$ & $(0,6389)$ & $(0,5291)$ & $(0,7773)$ & $(0,2405)$ \\
\hline \multirow[t]{2}{*}{ M1[i] } & & & & & 1 & 2,7183 & $1,9353 * *$ & $6,9262 * *$ \\
\hline & & & & & 0 & 0,0000 & $(0,7921)$ & $(5,4861)$ \\
\hline \multirow[t]{2}{*}{ Constant } & $-13,523 * * *$ & $0,0000 * * *$ & $-8,1218 * * *$ & $0,0003^{* * *}$ & $-11,733 * * *$ & $0,0000 * * *$ & $-2,894$ & 0,0554 \\
\hline & $(2,8492)$ & 0,0000 & $(1,7836)$ & $(0,0005)$ & $(3,8776)$ & 0,0000 & $(4,8198)$ & $(0,2668)$ \\
\hline \multicolumn{9}{|l|}{$\operatorname{var}(\mathrm{M} 1[\mathrm{i}])$} \\
\hline \multirow[t]{2}{*}{ Constant } & & & & & 0,9800 & 2,6645 & & \\
\hline & & & & & $(0,9059)$ & $(2,4136)$ & & \\
\hline Obs. & \multicolumn{4}{|c|}{1037} & \multicolumn{4}{|c|}{1037} \\
\hline $\begin{array}{l}\text { Log } \\
\text { likelihood }\end{array}$ & \multicolumn{4}{|c|}{$-246,700$} & \multicolumn{4}{|c|}{$-231,200$} \\
\hline$\overline{\mathrm{AIC}}$ & \multicolumn{4}{|c|}{525,315} & \multicolumn{4}{|c|}{498,379} \\
\hline $\mathrm{BIC}$ & \multicolumn{4}{|c|}{604,421} & \multicolumn{4}{|c|}{587,372} \\
\hline LR test & \multicolumn{2}{|c|}{30,940} & & Test & de Cramer & e Ridder (19) & & \\
\hline $\begin{array}{l}\text { P-valor LR } \\
\text { test }\end{array}$ & 0,00 & & $\begin{array}{c}\mathrm{P}>\operatorname{chi} 2= \\
01: 02\end{array}$ & 0,0110 & $\begin{array}{c}\mathrm{P}>\mathrm{chi} 2= \\
01: 00\end{array}$ & 0,0000 & $\begin{array}{c}\mathrm{P}>\mathrm{chi} 2= \\
02: 00\end{array}$ & 0,0050 \\
\hline
\end{tabular}

*** $\mathrm{p}<0,01, * * \mathrm{p}<0,05, * \mathrm{p}<0,1$. Erros padrão em parêntese.

pred_mul_cf - Percentual do número de diretores do gênero feminino sobre o número total de membros do conselho fiscal. pred_mul_ca - Percentual do número de diretores do gênero feminino sobre o número total de membros do conselho de administração.

pred mul_c_dir - Percentual do número de diretores do gênero feminino sobre o número total de membros da diretoria executiva.

ln_ativo_total - Log natural do ativo total.

tip_bco - Dummy para bancos múltiplos e comerciais.

estat - Dummy para bancos de controle estatal (governo federal, estadual ou municipal).

crise - Dummy para indicar o período da crise subprime (Julho de 2007 a abril de 2009).

M1[i] - Intercepto aleatório

Fonte: Elaborada segundo resultados da pesquisa

\section{Conclusões}

Esta pesquisa objetivou investigar a ocorrência de fraudes corporativas em instituições bancárias brasileiras, no período de janeiro de 2001 a dezembro de 2012, utilizando variáveis de detecção extraídas da teoria da agência e da economia do crime, agrupadas de acordo com as dimensões do triângulo de fraude de Cressey (1953): pressão, oportunidade e racionalização.

Constatou-se, para a dimensão de pressão, que o desempenho da instituição bancária no trimestre anterior possui um comportamento inverso com a probabilidade de ocorrência de fraudes corporativas. Destarte, um desempenho abaixo do esperado no período anterior pressionará o gestor quanto a desempenhos melhores futuros, e isso se refletirá no aumento da probabilidade de esse gestor perpetrar fraudes corporativas. Portanto, o desempenho abaixo do 
ideal é um tipo de pressão organizacional ao qual o gestor estará subordinado.

Para a dimensão de oportunidade, confirmou-se que instrumentos fracos de governança corporativa impactam positivamente na perpetração de fraudes. Os achados da pesquisa harmonizam-se com o que a teoria da agência postula sobre o monitoramento de gestores realizado pelos proprietários, demonstrando que a qualidade da firma de auditoria, classificada como uma big five, influencia negativamente a perpetração de fraudes. Esse achado corrobora a pesquisa de Lennox e Pittman (2010), em que empresas de auditoria big five conduzem genuinamente a melhores auditorias. A adesão a elementos adicionais de governança corporativa, como os selos de governança corporativa da BM\&F Bovespa, implicam em uma redução da probabilidade de ocorrência de fraudes corporativas.

Já para a dimensão de racionalização, foram utilizadas as características demográficas dos gestores para acessar a sua estrutura cognitiva, dada a dificuldade de obtenção de dados psicométricos convencionais de altos executivos, segundo Hambrick (2007). Dentre essas características foram analisadas a idade dos CEOs, e a predominância do gênero feminino na administração, além de instrumentos de punição. Confirmou-se, somente, que a predominância do gênero feminino na diretoria executiva contribui com a redução da probabilidade de ocorrência de fraudes corporativas.

Ressalte-se que embora não tenham sido confirmadas todas as hipóteses individuais delineadas nesta pesquisa, alguns outros resultados merecem ser destacados, como: a remuneração fixa dos gestores, a convergência às normas internacionais de contabilidade, a crise subprime e instituições com controle estatal.

A remuneração fixa dos gestores demonstrou um comportamento inverso com a probabilidade de fraudes corporativas. Tal fato permite confirmar que os incentivos de remuneração fixa moderam o comportamento do gestor, o que está de acordo com os escritos da teoria da agência.

A convergência às normas internacionais de contabilidade influenciou negativamente a probabilidade de fraudes. Esse resultado permite inferir que a convergência resultou em uma maior qualidade dos demonstrativos financeiros.

Como a convergência, a crise subprime também indicou um comportamento inverso com a possibilidade de fraudes. Dada a característica da crise, pode-se entender que esse evento exerceu uma limitação na predisposição dos gestores a assumirem maiores riscos, em função da alta exposição a que as instituições bancárias foram submetidas.

Portanto, os achados permitiram a investigação da ocorrência de fraudes corporativas, pela criação de modelos econométricos operacionalizados por variáveis extraídas da teoria da agência e economia do crime, agrupadas no triângulo de fraude de Cressey.

Foram identificadas limitações para a realização do estudo durante o processo de coleta de dados, em função da existência de poucas instituições que apresentaram a totalidade de sua série de dados disponível para o período analisado. Tal fato impactou, principalmente, na obtenção de informações sobre as características demográficas dos gestores, o que trouxe consequências à mensuração das hipóteses de pesquisa relacionadas a esse tipo de variável.

Pode-se considerar também como limitação da pesquisa a delimitação temporal. Conforme já evidenciado, a coleta de dados se deu para o período entre janeiro de 2001 a dezembro de 2012. Isto pelo fato de que o Banco Central do Brasil desobrigou as instituições financeiras, por força da Circular 3.630 de 2013, a apresentarem as informações financeiras trimestrais a partir de janeiro de 2013, inviabilizando, deste modo, a obtenção de dados dos trimestres de 2013 e 2014 até a presente data.

Ainda, para futuras pesquisas sugere-se, ainda, a replicação desta pesquisa a outros setores de atividade. Como também a utilização de outra proxy para identificação de fraudes, os processos judiciais. 


\section{Referências}

ALCHIAN, A. A.; DEMSETZ, H. Production , Information Costs , and Economic Organization. The American Economic Review, v. 62, n. 5, p. 777-795, 1972.

ALEXANDER, C. R.; COHEN, M. A. New Evidence on the Origins of Corporate Crime.

Managerial and Decision Economics, v. 17, p. 421-435, 1996. DOI: http://dx.doi.org/10.1002/(SICI)1099-1468(199607)17:4\%3C421::AIDMDE771\%3E3.0.CO;2-U

AMERICAN INSTITUTE OF CERTIFIED PUBLIC ACCOUNTANTS (AICPA).

Statement on Auditing Standards No. 99. Consideration of Fraud in a Financial Statement Audit. New York: AICPA, p. 163-214, 2002.

BANCO CENTRAL DO BRASIL. Circular 3.630, de 29 de fevereiro de 2013. Dispensa as instituições financeiras e demais instituições autorizadas a funcionar pelo Banco Central do Brasil da elaboração e remessa do documento Informações Financeiras Trimestrais (IFT). Disponível em: < http://www.bcb.gov.br/pre/normativos/>. Acesso em: 07 de nov. de 2013.

BANCO CENTRAL DO BRASIL. Resolução no 3.786, de 24 de setembro de 2009. Dispõe sobre a elaboração e a divulgação de demonstrações contábeis consolidadas com base no padrão contábil internacional emitido pelo International Accounting Standards Board (IASB). Disponível em: < http://www.bcb.gov.br/pre/normativos>. Acesso em: 07 nov. 2013.

BEASLEY, M. S. Empirical Analysis the of Board the Relation of Financial Between Composition Statement Fraud. The Accounting Review, v. 71, n. 4, p. 443-465, 1996.

BERGER, A. N. et al. Corporate Governance and Bank Performance: A joint analysis of the static, selection, and dynamic effects of domestic, foreign, and state ownership. Journal of Banking \& Finance, v. 29, n. 8-9, p. 2179-2221, 2005. DOI: http://dx.doi.org/10.1016/j.jbankfin.2005.03.013

BM\&F BOVESPA. Selos de Governança Corporativa: a marca do compromisso. Disponível em $<$ http://www.bmfbovespa.com.br/pt-br/servicos/solucoes-paraempresas/visibilidade-empresarial >. Acesso em: 07 de ago. de 2014.

BRAZEL, J. F.; JONES, K. L.; ZIMBELMAN, M. F. Using Nonfinancial Measures to Assess Fraud Risk. Journal of Accounting Research, v. 47, n. 5, p. 1135-1166, 2009. DOI: http://dx.doi.org/10.1111/j.1475-679X.2009.00349.x

BRITO, R. Comissão pedirá dados à SEC de apuração sobre Petrobras. Exame. São Paulo, 27 nov. 2014. Disponível em: $<$ http://exame.abril.com.br/brasil/noticias/comissao-pedira-dadosa-sec-de-apuracao-sobre-petrobras>. Acesso em: 29 nov. 2014.

BYRD, J.; PARRINO R.; PRITSCH, G.. Stockholder-Manager Conflicts and Firm Value. Financial Analysts Journal, v. 54, n. 3, p. 14-30, 1998. DOI: http://dx.doi.org/10.2469/faj.v54.n3.2177

COENEN, T L. Essential of Corporate Fraud. New Jersey: John Wiley \& Sons, 2008. DOI: http://dx.doi.org/10.1002/9781118386156

CONSELHO FEDERAL DE CONTABILIDADE. Resolução n 1.207 de 27 de novembro de 2009. Aprova a NBC TA 240 - Responsabilidade do Auditor em Relação a Fraude, no Contexto da Auditoria de Demonstrações Contábeis. Disponível em:< http://www.cfc.org.br $>$. Acesso em: 07 nov. 2013. 
CRAMER, J. S.; RIDDER, G. Pooling States in the Multinomial Logit Model. Journal of Econometrics, v. 47, p. 267-272, 1991. DOI: http://dx.doi.org/10.1016/0304-4076(91)90102$\mathrm{J}$

CRESSEY, D. R. Other People's Money: A study in the social psychology of embezzlement. Glencoe, IL: The free press, 1953.

CRUTCHLEY, C. E.; JENSEN, M. R. H.; MARSHALL, B. B. Climate for Scandal : Corporate Environments that Contribute to Accounting Fraud. The Financial Review, v. 42, p. 53-73, 2007. DOI: http://dx.doi.org/10.1111/j.1540-6288.2007.00161.x

DECHOW, P. M.; SLOAN, R. G.; SWEENEY, A. P. Causes and Consequences of Earnings Manipulation: An analysis of firms subject to enforcement actions by the SEC.

Contemporary Accounting Research, v. 13, n. 1, p. 1-36, 1996. DOI: http://dx.doi.org/10.1111/j.1911-3846.1996.tb00489.x

ERICKSON, M.; HANLON, M.; MAYDEW, E. L. Is There a Link between Executive Equity Incentives and Accounting Fraud? Journal of Accounting Research, v. 44, n. 1, p. 113-143, 2006. DOI: http://dx.doi.org/10.1111/j.1475-679X.2006.00194.x

FAMA, E. F. Efficient Capital Markets: A Review of Theory and Empirical Work. The Journal of Finance, v. 25, n.2, p. 383-417, 1970. DOI: http://dx.doi.org/10.2307/2325486

FIELDS, T. D.; LYS, T. Z.; VINCENT, L. Empirical research on accounting choice. Journal of Accounting and Economics, v. 31, p. 255-307, set. 2001. DOI:

http://dx.doi.org/10.1016/S0165-4101(01)00028-3

GARTNER, I. R. Modelagem Multiatributos Aplicada à Avaliação do Desempenho Econômico-Financeiro de Empresas. Pesquisa Operacional, v. 30, n. 3, p. 619-636, 2010.

GOLDBERG, V. P. Regulaffon and administered contracts. The Bell Journal of Economics, v. 7, n. 2, p. 426-448, 1976.

GRELLET, F. PF busca provas de fraude nos Correios do Rio. Exame. São Paulo, 27 nov. 2014. <http://exame.abril.com.br/brasil/noticias/pf-busca-provas-de-fraude-nos-correios-dorio>. Acesso em: 29 nov. 2014.

GRILLI, L.; RAMPICHINI, C. A Multilevel Multinomial Logit Model for the Analysis of Graduates' Skills. Statistical Methods and Applications, v. 16, n. 3, p. 381-393, 2007.

HAAN, P.; UHLENDORFF, A. Estimation of Multinomial Logit Models with Unobserved Heterogeneity using Maximum Simulated Likelihood. The Stata Journal, v. 6, n. 2, p. 229$245,2006$.

HAMBRICK, D. C. Upper Echelons Theory: An Update. The Academy of Management Review, v. 32, n. 2, p. 334-343, 2007. DOI: http://dx.doi.org/10.5465/AMR.2007.24345254

HAYNES, M.; WESTERN, M.; SPALLEK, M.. Methods for Categorical Longitudinal Survey Data: Understanding Employment Status of Australian Women. In: HILDA Survey Research Conference,. 2005, Melbourne. Anais... Melbourne: University of Melbourne, p. 124

HILBE, J. M. Logistic Regression Models. New York: CRC Press, 2009.

JENSEN, C.; MECKLING, H. Theory of the Firm: Managerial Behavior, Agency Costs and Ownership Structure. Journal of Financial Economics, v. 3, p. 305-360, 1976. DOI: http://dx.doi.org/10.1016/0304-405X(76)90026-X 
JENSEN, M. C. Agency Costs of Free Cash Flow, Corporate Finance, and Takeovers. The American Economic Review, v. 76, n. 2, p. 323-329, 1986.

JENSEN, M. C.; MURPHY, K. J. Performance Pay and Top-Management Incentives. Journal of Political Economy, v. 98, n. 2, p. 225-264, 1990. DOI: http://dx.doi.org/10.1086/261677

JOHN, K.; SENBET, L. W. Corporate Governance and Board e Effectiveness. Journal of Banking \& Finance, v. 22, p. 371-403, 1998. DOI: http://dx.doi.org/10.1016/S03784266(98)00005-3

KELLEY, S. W.; FERRELL, O. C.; SKINNER, S. J. Ethical Behavior Among Marketing Researchers : An Assessment of Selected Demographic Characteristics. Journal of Business Ethics, v. 9, p. 681-688, 1990. DOI: http://dx.doi.org/10.1007/BF00383395

LENNOX, C.; PITTMAN, J. A. Big Five Audits and Accounting Fraud. Contemporary Accounting Research, v. 27, n. 1, p. 209-247, 2010. DOI: http://dx.doi.org/10.1111/j.19113846.2010.01007.x

LOCHNER, L. Education, Work, and Crime: A human capital approach. International Economic Review, v. 45, n. 3, p. 811-843, 2004. DOI: http://dx.doi.org/10.1111/j.00206598.2004.00288.x

LONG, J. S.; FREESE, J. Regression Models for Categorical Dependent Variables Using Stata. 2. ed. Texas: Stata Press, 2006.

LOU, Y.; WANG, M. Fraud Risk Factor Of The Fraud Triangle Assessing The Likelihood Of Fraudulent Financial Reporting. Journal of Business \& Economics Research, v. 7, n. 2, p. 61-78, 2009. DOI: http://dx.doi.org/10.19030/jber.v7i2.2262

MACEY, J. R. Agency Theory and the Criminal Liability of Organizations. Boston University Law Review, v. 71, p. 315-340, 1991.

MACIEL, L. et al. Impacto dos Contratos Futuros do Ibovespa na Volatilidade dos Índices de Ações no Brasil: Uma análise na crise do subprime. Estudos econômicos, v. 42, p. 801-825, 2012.

MARKIN, R. J. The role of rationalization in consumer decision processes: A revisionist approach to consumer behavior. Journal of the Academy of Marketing Science, v. 7, n. 4, p. 316-334, 1979. DOI: http://dx.doi.org/10.1007/BF02729682

MATOUSEK, R. et al. Bank Performance and Convergence During the Financial Crisis: Evidence from the "old" European Union and Eurozone. Journal of Banking \& Finance, v. xxx, p. 2 - 9, 2014. DOI: http://dx.doi.org/10.1016/j.jbankfin.2014.08.012

MINISTÉRIO PÚBLICO FEDERAL - MPF. Procuradores da Força Tarefa concederão entrevista coletiva, às 14h, na sede do MPF/Paraná, em Curitiba. Curitiba, 22 ago. 2014. Disponível em $<$ http://www.prpr.mpf.mp.br/news/operacao-lava-jato-cumprimento-de-novosmandados-de-busca-e-apreensao-criminal $/$ ? searchterm=petrobr $\% \mathrm{C} 3 \% \mathrm{~A} 1 \mathrm{~s} />$. Acesso em: 07 set. 2014.

POSNER, R. A. Economic analysis of law. 7. ed. Chicago: Aspen Publishers, 2007.

PRIMO, U. R. et al. Determinantes da rentabilidade bancária no Brasil. BASE - Revista de Administração e Contabilidade da Unisinos, v. 10, n. 4, p. 308-323, 2013.

RAHN, W. M.; KROSNICK, J. A.; BREUNING, M. Rationalization and Derivation 
Processes in Survey Studies of Political Candidate Evaluation. American Journal of Political Science, v. 38, n. 3, p. 582-600, 1994.

REYNOLDS, S. J. A Neurocognitive Model of the Ethical Decision-Making Process: Implications for Study and Practice. The Journal of applied psychology, v. 91, n. 4, p. 737 48, 2006. DOI: http://dx.doi.org/10.1037/0021-9010.91.4.737

ROSEN, Sherwin. Contracts and the Market for Executives. National Bureau of Economic Research, 1990. Disponível em: <http://www.nber.org/papers/w3542>. Acesso em: 07 jul. 2013.

ROSS, S. A. The Economic The Theory of Agency : Principal's Problem. The American Economic Review, v. 63, n. 2, p. 134-139, 1973.

RYAN, H. E.; WIGGINS, R. A. The influence of firm- and manager-specific characteristics on the structure of executive compensation. Journal of Corporate Finance, v. 7, n. 2, p. 101-123, 2001. DOI: http://dx.doi.org/10.1016/S0929-1199(00)00021-3

SADKA, G. The Economic Consequences of Accounting Fraud in Product Markets: Theory and a Case from the U.S. Telecommunications Industry (WorldCom). American Law and Economics Review, v. 8, n. 3, p. 439-475, 2006.

SCHEUFELE, D. A. Agenda-Setting, Priming, and Framing Revisited: Another Look at Cognitive Effects of Political Communication. Mass Comunication \& Society, v. 3, n. 2/3, p. 297-316, 2000. DOI: http://dx.doi.org/10.1207/S15327825MCS0323_07

SCHRAND, C. M.; ZECHMAN, S. L. C. Executive overconfidence and the slippery slope to financial misreporting. Journal of Accounting and Economics, v. 53, n. 1-2, p. 311-329, fev. 2012. DOI: http://dx.doi.org/10.1016/j.jacceco.2011.09.001

SILVA, A. L. C. Governança Corporativa, Valor, Alavancagem e Política de Dividendos das Empresas Brasileiras. Revista de Administração, v. 39, n. 4, p. 348-361, 2004.

SINGLETON, T. W.; SINGLETON, A. J. Fraud Auditing and Forensic Accounting. 4. ed. Hoboken: John Wiley \& Sons, Inc., 2010. DOI: http://dx.doi.org/10.1002/9781118269183

SKRONDAL, A.; RABE-HESKETH, S. Generalized Latent Variable Modeling:

Multilevel, longitudinal and structural equation models. New York: Chapman \& Hall/CRC, 2004. DOI: http://dx.doi.org/10.1201/9780203489437

SKRONDAL, A.; RABE-HESKETH, S. Multilevel Logistic Regression for Polytomous Data and Rankings. Psychometrika, v. 68, n. 2, p. 267-287, 2003. DOI:

http://dx.doi.org/10.1007/BF02294801

STEFFENSMEIER, D. J.; SCHWARTZ, J.; ROCHE, M. Gender and Twenty-First-Century Corporate Crime: Female Involvement and the Gender Gap in Enron-Era Corporate Frauds. American Sociological Review, v. 78, n. 3, p. 448-476, 2013. DOI: http://dx.doi.org/10.1177/0003122413484150

TRAIN, K. E. Discrete Choice Methods with Simulation. 2. ed. Cambridge: Cambridge University Press, 2003. DOI: http://dx.doi.org/10.1017/CBO9780511805271

TRAPP, A. C. G. A Relação do Conselho Fiscal como Componente de Controle no Gerenciamento de Resultados Contábeis. 2009. 133 f. Tese (Doutorado em Ciências Contábeis). Departamento de Contabilidade e Atuária da Faculdade de Economia, Administração e Contabilidade da Universidade de São Paulo, São Paulo, 2009. 
TROY, C.; SMITH, K. G.; DOMINO, M. A. CEO demographics and accounting fraud: Who is more likely to rationalize illegal acts? Strategic Organization, v. 9, n. 4, p. 259-282, 2011. DOI: http://dx.doi.org/10.1177/1476127011421534

TYMOIGNE, É.. Securitization, Deregulation, Economic Stability, and Financial Crisis. Part I: The evolution of securitization. Working paper, Nova York, Levy Economics Institute, 2009. DOI: http://dx.doi.org/10.2139/ssrn.1458408

WANG, T. Y. Corporate Securities Fraud: Insights from a New Empirical Framework. Journal of Law, Economics, and Organization, v. 9, p. 1-34, 2011. DOI: http://dx.doi.org/10.1093/jleo/ewr009

WANG, T. Y. U. E.; WINTON, A.; YU, X. Corporate Fraud and Business Conditions: Evidence from IPOs. The Journal of Finance, v. LXV, n. 6, p. 2255-2292, 2010. DOI: http://dx.doi.org/10.1111/j.1540-6261.2010.01615.x

WANG, T.; HSU, C. Board composition and operational risk events of financial institutions. Journal of Banking \& Finance, v. 37, n. 6, p. 2042-2051, 2013. DOI: http://dx.doi.org/10.1016/j.jbankfin.2013.01.027

ZAHRA, S. A.; PRIEM, R. L.; RASHEED, A. A. Understanding the Causes and Effects of Top Management Fraud. Organizational Dynamics, v. 36, n. 2, p. 122-139, 2007. DOI: http://dx.doi.org/10.1016/j.orgdyn.2007.03.002 